\title{
Knock Detection in Spark Ignition Engines Base on Complementary Ensemble Empirical Mode Decomposition-Hilbert Transform
}

\author{
Fengrong Bi, Teng Ma, Jian Zhang, Lin Li, and Chunfang Shi
}

State Key Laboratory of Engines, Tianjin University, Tianjin 300072, China

Correspondence should be addressed to Teng Ma; mxc200523@sina.com

Received 31 October 2015; Revised 28 January 2016; Accepted 2 February 2016

Academic Editor: Mohamed El badaoui

Copyright (C) 2016 Fengrong Bi et al. This is an open access article distributed under the Creative Commons Attribution License, which permits unrestricted use, distribution, and reproduction in any medium, provided the original work is properly cited.

In spark ignition engines, knock onset limits the maximum spark advance. An inaccurate identification of this limit penalises the fuel conversion efficiency. Thus knock feature extraction is the key of closed-loop control of ignition in spark ignition engine. This paper reports an investigation of knock detection in spark ignition (SI) engines using CEEMD-Hilbert transform based on the engine cylinder pressure signals and engine cylinder block vibration signals. Complementary Ensemble Empirical Mode Decomposition (CEEMD) was used to decompose the signal and detect knock characteristic. Hilbert transform was used to analyze the frequency information of knock characteristic. The result shows that, for both of cylinder pressure signals and vibration signals, the CEEMD algorithm could extract the knock characteristic, and the Hilbert transform result shows that the energy of knock impact areas has the phenomenon of frequency concentration in both cylinder pressure signal and cylinder block vibration signal. At last, the knock window is then determined, based on which a new knock intensity evaluation factor $K$ is propose, and it can accurately distinguish between heavy knock, light knock, and normal combustion three states.

\section{Introduction}

In the recent years, the reduction of fuel consumption has become a mandatory goal in the development of internal combustion engines [1]. With the purpose of high torque output and low fuel consumption, compression ratio (CR) has to be increased or turbocharger has to be taken in modern SI engines to improve thermal efficiency [2]. However, as the engine thermal efficiency is improving, the probability of occurrence for knocking in the engine is also increasing; heavy knock leads to reduce engine performance and cause unpleasant noise and structural vibration. Meanwhile light knock can improve the power performance of an engine. Therefore, it has been a main challenge for current SI engines to extract knock characteristic and evaluate knock intensity.

Engine knock is defined as abnormal combustion induced by autoignition in the combustion chamber. Both inhomogeneous mixture composition and temperature distribution in the end gas affect the location of autoignition centers [3]. When the knock occurs, high frequency oscillation pressure waves will be created within the combustion chamber and induce high frequency vibration of cylinder block.

The popular and valid approach is to measure knock impact by using several types of sensors such as pressure sensors and acceleration sensors [4]. Cylinder pressure oscillations clearly indicate what happens during a knock cycle inside the combustion chamber. But the cylinder pressure sensors are very expensive. So the most widely used method of measuring knock is using a simple acceleration senor attached to the cylinder block. This method is an easy and cost-effective task. However, vibrations induced by resonances in the combustion chamber have to be detected against a complex background of heavy noise and other vibrations. Vibration signal need to be reprocessed.

Signal transform techniques are useful tools for knock detection methods, such as fast Fourier transform (FFT [5]), short-time Fourier transform (STFT [6]), Wigner-Ville 
distribution (WVD [7]), cyclostationary signal analysis [8], continuous wavelet transform (CWT $[9,10]$ ), discrete wavelet transform (DWT [11, 12]), and nonlinear wavelet transform (NWT [13]). These methods have been utilized to analyze engine vibration signals for detect knock. But these methods have their weakness. FFT cannot reflect the time domain information of signal. STFT can reflect signal's time domain information but the time window is fixed. Actually, in the process of analyzing the knock signal, we want analysis of signal's high frequency components and low frequency components with different precision. But resolution of STFT is fixed and cannot adapt to the requirement of signal change. Wavelet transform has the features of high resolution and can solve the problems existing in the STFT. But the result of wavelet analysis is restricted by selected wavelet bases, and when the signal frequency is mutation, the result of wavelet is not ideal. Hilbert transform can accurately reflect the distribution of the signal energy in both time domain and frequency domain. But, for a nonstationary signal, if using Hilbert transformed directly, the original physical meaning will be lost. And the signal after the Complementary Ensemble Empirical Mode Decomposition (CEEMD) decomposes gets some intrinsic mode functions (IMFs); each IMF component is stationary. So the CEEMD needs to be done. And, in this paper, on the basis of CEEMD-Hilbert transforms, SI engine knock detection approach using engine cylinder pressure signal and cylinder block vibration signals is proposed.

\section{Methods}

\subsection{CEEMD Algorithm}

2.1.1. EMD Algorithm. For a real-valued signal, $x(t)$, standard EMD finds a set of IMFs, and the IMFs are defined so as to have symmetric upper and lower envelopes with the number of zero crossings and the number of extreme differing at most by one. To extract IMFs, an iterative process called sifting algorithm is employed, which is described below [14]:

(1) Find the locations of all the extrema of $x(t)$.

(2) Interpolate between all the minima to obtain the lower signal envelope on $u(t)$. Interpolate between all the maxima to obtain the upper signal envelope, $v(t)$.

(3) Compute the local mean:

$$
m_{1}(t)=\frac{u(t)+v(t)}{2} .
$$

(4) Subtract the mean from $x(t)$ to obtain the "oscillatory mode", $h_{1}(t)$ :

$$
h_{1}(t)=x(t)-m_{1}(t) .
$$

(5) If $h_{1}(t)$ meet the required conditions, then define $c_{1}(t)=h_{1}(t)$ as the first IMF; otherwise, set new $x(t)=h_{1}(t)$ and repeat the process from Step (1).

The same procedure is applied iteratively to the residue, $r=x(t)-c_{1}$, to extract other IMFs.
2.1.2. Mode Mixing. Although EMD process is an ideal approach for decomposing nonstationary and complicated nonlinear signals, it suffers from some deficiencies, one of which is the mode mixing. Mode mixing is a characteristic of a single IMF consisting of either signals of widely disparate scales or signals of similar scales residing in different IMFs. Mode mixing would not only cause frequency aliasing between two IMFs but also damage the physical meaning of a certain IMF [15].

2.1.3. EEMD Algorithm. In order to alleviate the problem of EMD, Ensemble Empirical Mode Decomposition (EEMD) is proposed by Wu and Huang, and this method defines the true IMF components as the mean of an ensemble of trials. Each trial consists of the decomposition results of the signal plus a white noise of finite amplitude [16]. This method can effectively inhibit the modal mixing caused by abnormal disturbance.

The procedure of the EEMD method can be briefly summarized as follows:

(1) Add white noise with predefined noise amplitude to the signal for analyzing.

(2) Use EMD method to decompose the newly generated signal.

(3) Repeat the above signal decomposition with different white noise, when the amplitude of the added white noise is fixed.

(4) Calculate the ensemble means of the decomposition results as final results.

2.1.4. The Problem of EEMD. The EEMD algorithm performs the EMD over an ensemble of the signal plus Gaussian white noise. The addition of white Gaussian noise solves the mode mixing problem by populating the whole time-frequency space to take advantage of the dyadic filter bank behavior of the EMD; however it creates some new ones.

The main question of EEMD method is the residue white noise. When we use EEMD method to extract knock characteristics, if the knock intensity are more mild, residual white noise will interfere the effect of knock feature extraction, although increased the average number of collections can reduce white noise residual, it will significantly increase the computation, and it is bad for the realization of knock characteristic real-time detection.

2.1.5. CEEMD Algorithm. Complementary EEMD (CEEMD) approach not only solves the mode mixing and white noise residues, but also improves the calculation efficiency of EEMD. CEEMD includes the following steps.

In the CEEMD method, white noise is added in pairs to the original data (one positive and one negative) to generate two sets of ensemble IMFs. Therefore, two mixtures composed of the original data can be added noise by the following method:

$$
\left[\begin{array}{l}
M_{1} \\
M_{2}
\end{array}\right]=\left[\begin{array}{cc}
1 & 1 \\
1 & -1
\end{array}\right]\left[\begin{array}{l}
S \\
N
\end{array}\right] .
$$



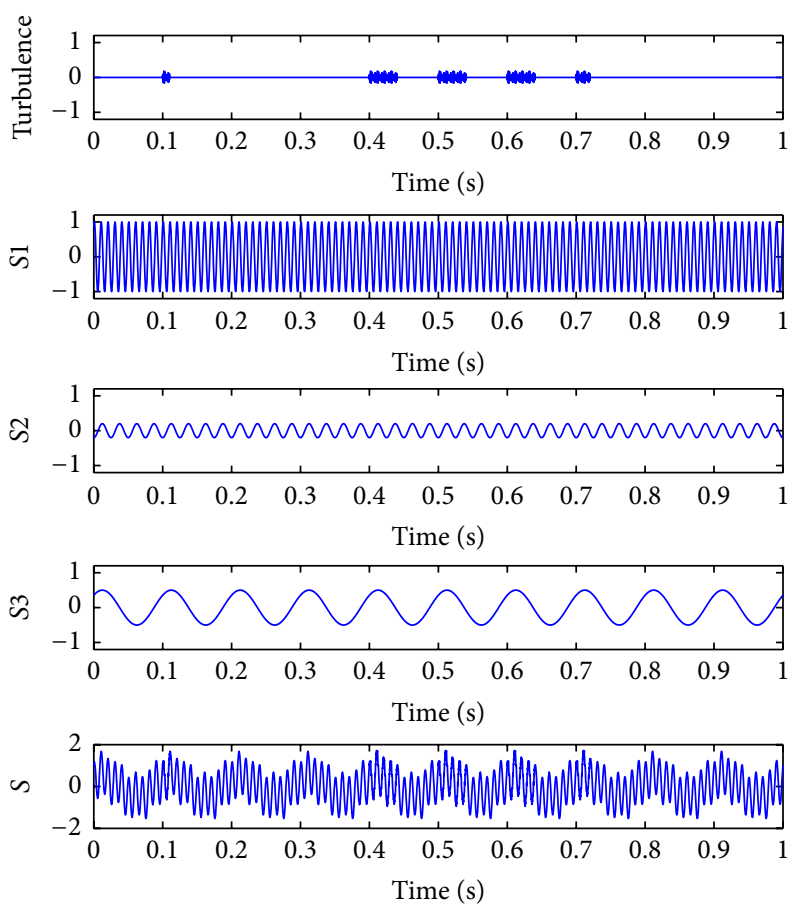

Figure 1: Original signal.

In the above equation, $S$ is the original data; $N$ is the added white noise; $M_{1}$ is the sum of the original data with positive noise; and $M_{2}$ is the sum of the original data with the negative noise.

Then, the ensemble IMFs obtained from those positive mixtures contribute to a set of IMFs with positive residues of added white noises like EEMD method. Similarly, the ensembles IMFs obtained from those negative mixtures and produce the negative residue of added white noises. Thus, the final IMF is the ensemble of both the IMFs with positive and negative noises [17].

To illustrate the advantage of CEEMD, a simulation signal is listed. In this experiment, the simulated signal contains three sinusoid waves having different initial phases, amplitudes, and frequencies and an intermittent signal. The main components of the simulated signal are given as

$$
\begin{aligned}
& S 1=\sin \left(2 \pi 100 t+\frac{\pi}{3}\right), \\
& S 2=0.2 \sin \left(2 \pi 40 t-\frac{\pi}{2}\right), \\
& S 3=0.5 \sin \left(2 \pi 10 t+\frac{\pi}{4}\right), \\
& S=S 1+S 2+S 3 .
\end{aligned}
$$

In addition, the intermittent sections of stochastic signal are appearing in different time points. The sinusoid waves and intermittent turbulence of the simulated signals are shown in Figure 1.

First, the original signal is analyzed by narrow-band filters. Since the original signal contain $10 \mathrm{~Hz}, 40 \mathrm{~Hz}$, and
$100 \mathrm{~Hz}$ frequency components, 3 filters were used to analyze this signal. The pass bands of 3 filters are $8-12 \mathrm{~Hz}, 38-42 \mathrm{~Hz}$, and $98-102 \mathrm{~Hz}$, respectively. The filter results are shown in Figure 2(a). From this figure, it can be found that after being analyzed by $8-12 \mathrm{~Hz}$ band pass filter, $S 3$ can be preserved well and others components have been filter out. However, the analysis results of $38-42 \mathrm{~Hz}$ band pass filter and 98$102 \mathrm{~Hz}$ band pass filter are not satisfactory. As is shown in Figure 2(a), the amplitude of $38-42 \mathrm{~Hz}$ band pass filter and 98-102 band filter is quite different between $S 2$ and $S 1$, and there is an obvious low frequency interference in the 38$42 \mathrm{~Hz}$ band pass filter result.

Then, decompose the original signal with EMD method; the results have six IMF components. The result is shown in Figure 2(b). From the figure it can be found that many parts of IMF 1 were replaced by the intermittent signal. The replaced parts of IMF 1 are shifted to IMF 2 resulting in the phenomenon of mode-mixing in the second and all the following IMFs.

The same simulated signal decomposed by EEMD, with 200 ensemble members and the RMS of noise signal is 0.2 times of the original signal, resulted in the IMFs as shown in Figure 2(c). In Figure 2(c), IMF1 and IMF2 show the mixture of the intermittent signals contaminated to certain degree by the added noise; IMF3-IMF5, respectively, represents $S 1$, $S 2$, and $S 3$ in the original signal. This result proved that the EEMD algorithm can solve the mode-mixing problem very well.

At last, the same simulated signal decomposed by CEEMD with 50 ensemble members and the RMS noise signal is 0.2 times that of the original signal; the decompose result is shown in the Figure 2(d). As is shown in Figure 2(d), 
$8-12 \mathrm{~Hz}$ band pass filter result

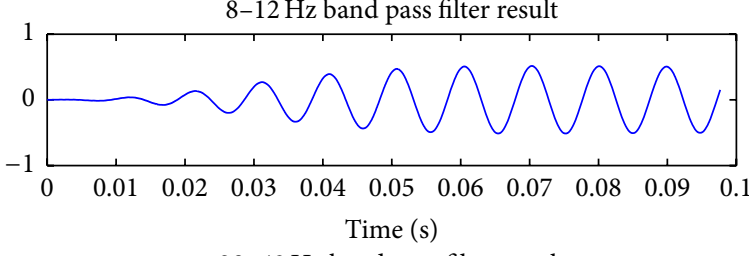

$38-42 \mathrm{~Hz}$ band pass filter result
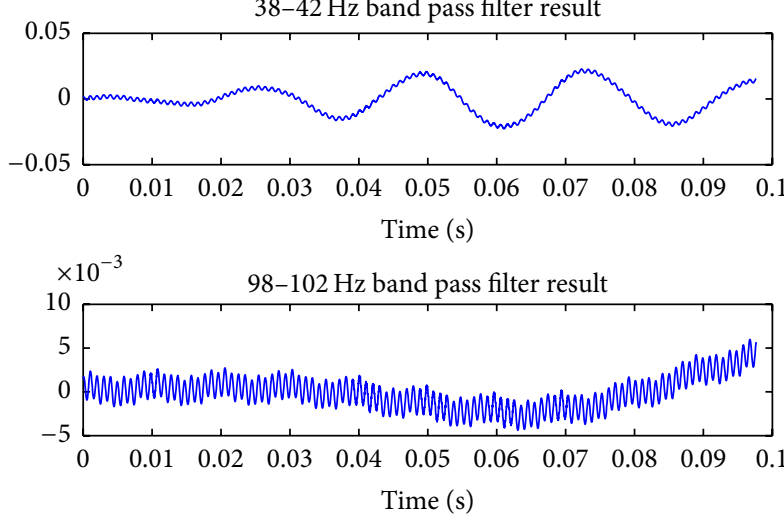

(a)
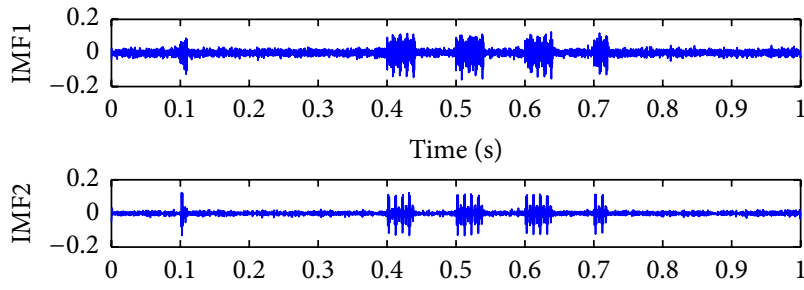

Time (s)

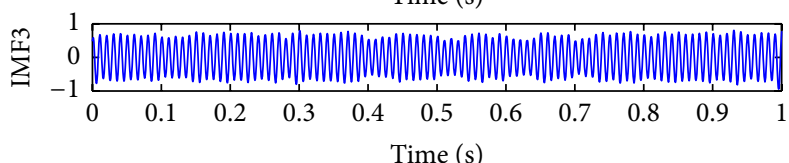

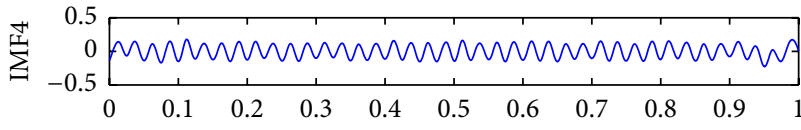

Time (s)

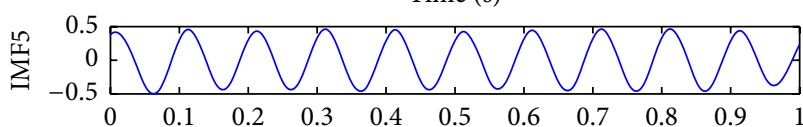

Time (s)

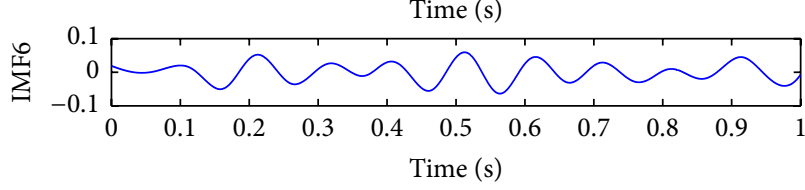

(c)

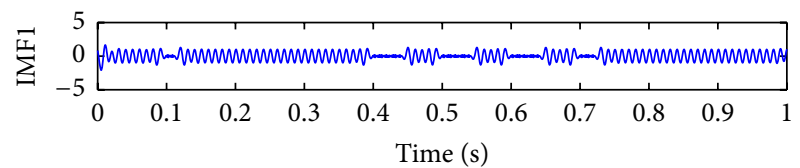

$\sum_{0}^{2}$
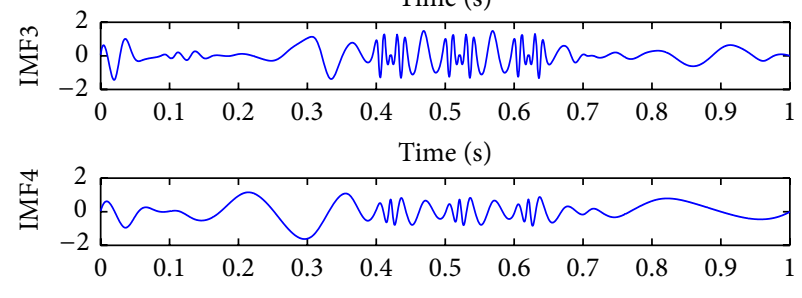

Time (s)
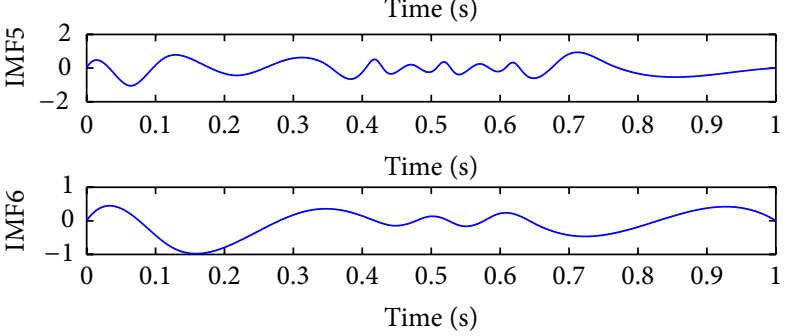

(b)

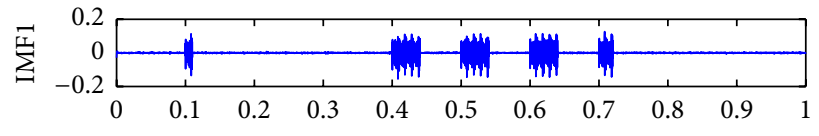

Time (s)
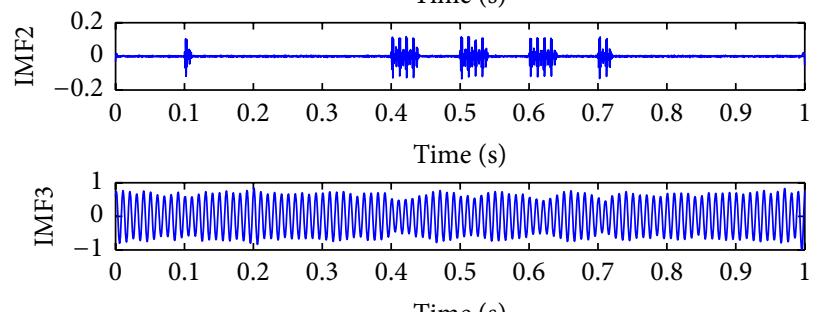

Time (s)
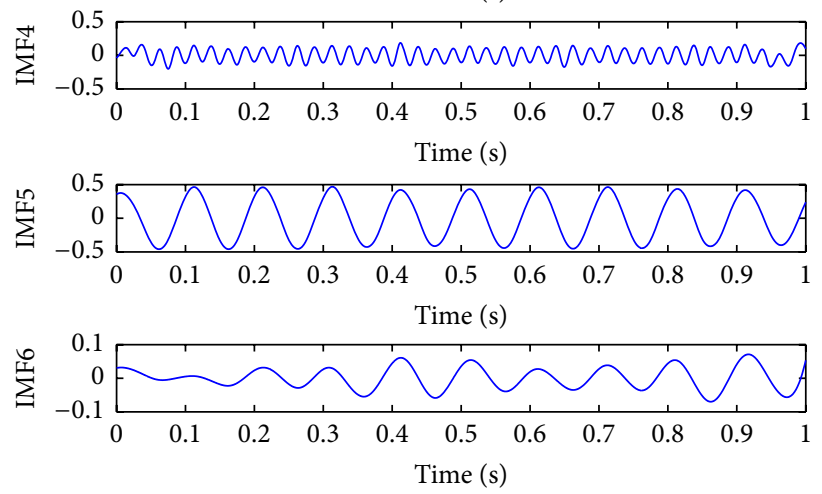

(d)

FIgURE 2: (a) The result of band pass filter. (b) The result of EMD. (c) The result of EEMD. (d) The result of CEEMD. 

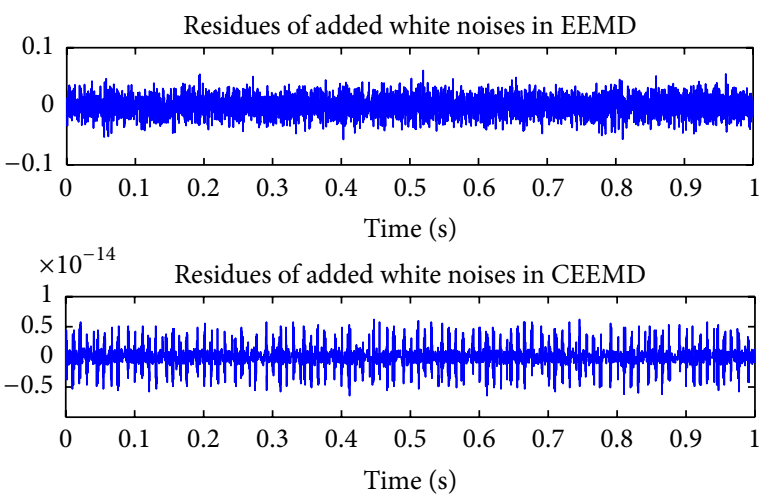

FIGURE 3: Residues of added white noises derived by EEMD and CEEMD.

visual comparison between the results of EEMD and CEEMD shows no significant difference; the CEEMD algorithm also can represent the characteristics of the original signal accurately; IMF3-IMF5 recovered the sinusoidal waves as the original constituting the components of the simulated signal. However, there is a significant difference between the residues of added white noise in the result. Figure 3 shows the residues of added white noise derived by EEMD and CEEMD. As is shown of Figure 3, the residue of white noise from EEMD has average amplitude around 0.1 ; the corresponding residue from CEEMD has average amplitude close to 0 . That means though EEMD method solve the mode mixing, but the noise residue increase. The CEEMD method not only solves the mode mixing but also eliminates the residue white noise. And the CEEMD method also can save the computation time because the paired noises could effectively reduce the final white noise residue.

2.2. Hilbert Transform. One of the important features of nonstationary signal (like knock signal) is that it has the timevarying spectra. Fourier analysis can reflect frequency information of the signal, but it cannot reflect the signal's timevarying frequency information. The frequency at a particular time is described as instantaneous frequency, which could extracted by the Hilbert transformation.

For an arbitrary time series, $X(t)$, we can always have its Hilbert Transform, $Y(t)$, as

$$
Y(t)=\frac{1}{\pi} P \int_{-\infty}^{+\infty} \frac{X(\tau)}{t-\tau} d \tau .
$$

In the above equation, $P$ is the Cauchy principal value. Due to this definition, $X(t)$ and $Y(t)$ form the complex conjugate pair, we have the analytic signal, $Z(t)$, as

$$
Z(t)=X(t)+i Y(t)=a(t) e^{i \theta(t)} .
$$

In which

$$
\begin{aligned}
& \theta(t)=\arctan \left(\frac{Y(t)}{X(t)}\right), \\
& a(t)=\left[X^{2}(t)+Y^{2}(t)\right]^{1 / 2} .
\end{aligned}
$$

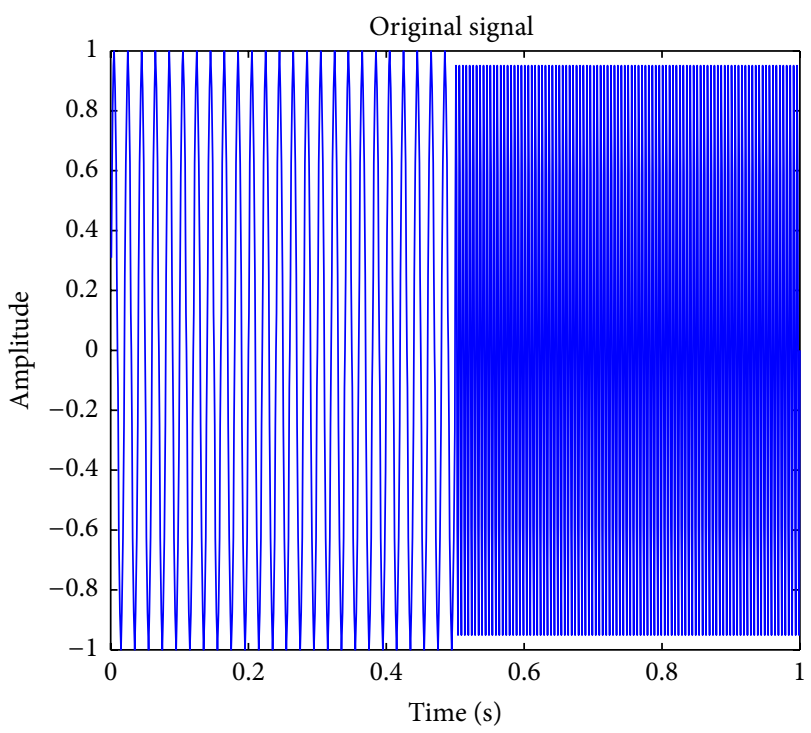

FIGURE 4: Original signal.

$a(t)$ is the instantaneous amplitude of $X(t)$, which can reflect that the energy of $X(t)$ varies with the time, and $Y(t)$ is the instantaneous phase of the $X(t)$.

And the instantaneous frequency is defined as follows:

$$
\omega(t)=\frac{d \theta}{d t} .
$$

To illustrate the effect of Hilbert Transform, we apply a simulation signal which is shown from below: The frequency of this signal is changed at $0.5 \mathrm{~s}$ :

$$
\begin{aligned}
& S=\sin 2 \pi \times 50 \times t \quad t \in[0,0.5], \\
& S=\sin 2 \pi \times 200 \times t \quad t \in[0.5,1] .
\end{aligned}
$$

The above signal has different frequency; the frequency of this signal is changed at $0.5 \mathrm{~s}$, but the amplitude of the signal remains 1. It is shown in Figure 4.

Figure 5 shows the result of Hilbert transform, the frequency changing can be identified clearly in the Figure 5(a), and, from Figure 5(b), it can be seen that the instantaneous amplitude is the same as the original signal.

\section{Engine Test Program and Experimental Data Acquisition}

In this test a 4-cylinder in-line SI engine was used to generate the test data. Main characteristics of the engine are shown in Table 1. In this experiment, engine knock was induced by varying the spark advance. The vibration acceleration signals are collected by a Dytran 621B40 acceleration sensor. In order to maximize the power of the knock motivation component in the measured signal, this acceleration sensor was mounted on the cylinder block of cylinder 2. Due to the fact that the engines have a lot of vibration source, the collected signals have much noise. In order to directly monitor the occurrence of knocking and to estimate the knock intensity in each 


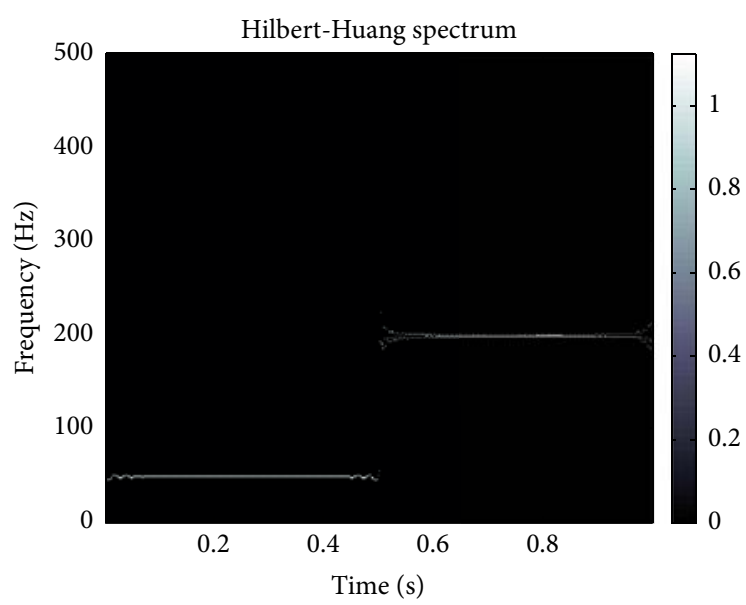

(a)
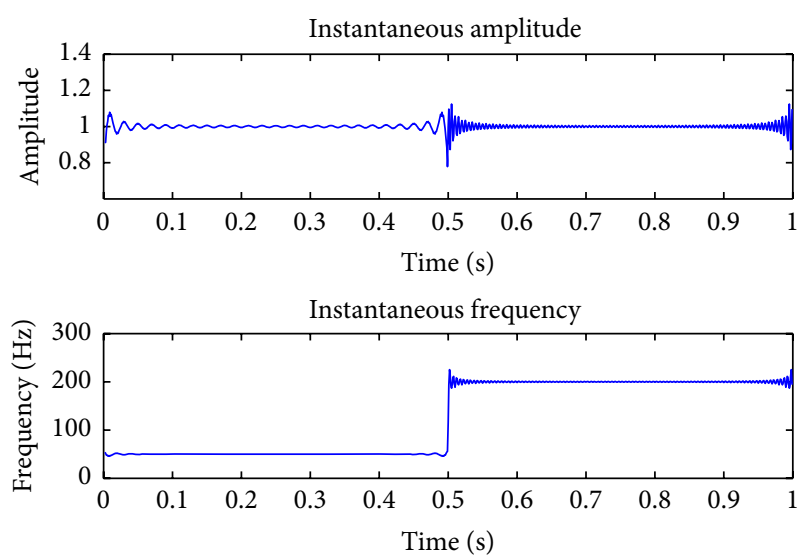

(b)

FIGURE 5: (a) The result of Hilbert spectrum. (b) The instantaneous amplitude and the instantaneous frequency.

TABLE 1: Test engine specifications.

\begin{tabular}{lc}
\hline Items description & Parameter \\
\hline Cylinders/valves per cyl & $4 / 4$ \\
Displacement & $1.5 \mathrm{~L}$ \\
Intake type & Turbocharge \\
Max power & $110 \mathrm{~kW} @ 5600 \mathrm{rpm}$ \\
Max torque & $210 \mathrm{Nm} @ 2200-4500 \mathrm{rpm}$ \\
\hline
\end{tabular}
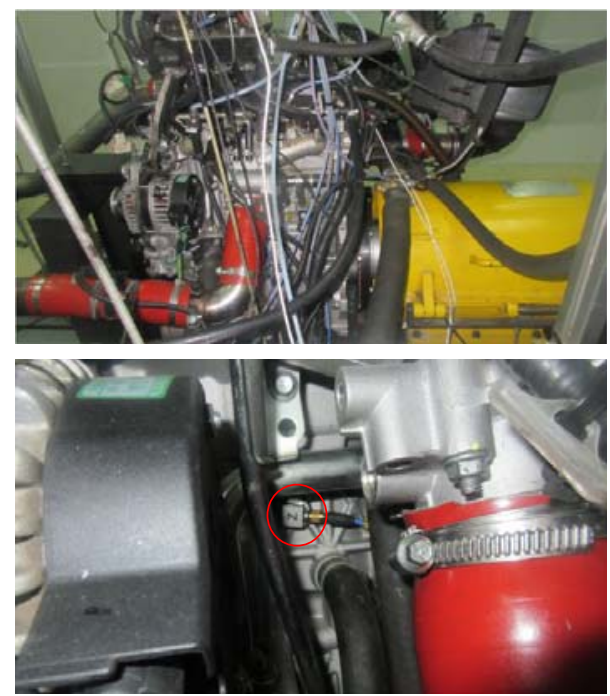

FIGURE 6: The locations of the vibration acceleration sensors on the test engine.

cylinder, 4 AVL GH13Z-31(24) pressure sensors were installed in the combustion chamber of each cylinder to measure the cylinder pressure. Data collected using the LMS Scada III noise and vibration testing system, the sampling frequency is selected as $51200 \mathrm{~Hz}$. The locations of acceleration sensors on the test engine are shown in Figure 6.
To collect the knock signals, the engine knock was induced by varying the spark advance. The engine operating condition was $2800 \mathrm{rpm}$ to $4000 \mathrm{rpm}$ and the load was varied from $70 \mathrm{Nm}$ to $190 \mathrm{Nm}$.

\section{Result}

4.1. Knock Feature Extraction. Figures $7(\mathrm{a})$ and $7(\mathrm{~b})$ shows the in-cylinder pressure and cylinder pressure increase rate curves of a typical knock condition under $4000 \mathrm{rpm}, 178 \mathrm{Nm}$ load, and the ignition advance angle is $15^{\circ} \mathrm{CA}$. From Figure 7 , it can be found that the cylinder pressure is fluctuating sharply near the peak pressure, and the pressure increase rate is over $2 \times 10^{11} \mathrm{~Pa} / \mathrm{s}$. And as is shown in Figure 7(c), the peak amplitude of vibration signal is over $150 \mathrm{~g}$.

Figures $8(\mathrm{a})-8(\mathrm{~b})$ are each cylinder pressure and pressure increase rate curve, Figure $8(\mathrm{c})$ is the second cylinder engine vibration curve at this moment. And the engine speed is $4000 \mathrm{rpm}$, torque is $151 \mathrm{Nm}$, and the ignition advance angle is $10^{\circ} \mathrm{CA}$.

As is shown in Figure 8(a), from left to right is the cylinder pressure signal of 3-4-2-1 cylinder. From Figure 8, it can be found that pressure signal of cylinder 1 and cylinder 3 cycles have fluctuations, and the cylinder 2 and cylinder 4 cycles do not have this phenomenon. In addition, the pressure increase rates of cylinder 1 and cylinder 3 cycles are larger than cylinder 2 and cylinder 4 cycles obviously. So it can be concluded that, in Figure 8, the cycles of cylinder 1 and cylinder 3 are knock conditions. And cylinder 2 and cylinder 4 cycles are normal conditions. But compared with the typical knock condition shown in Figure 7, the cylinder pressure fluctuation of cylinder 1 and cylinder 3 cycles shown in the Figure 8(a) is not sharp, and the pressure rise rate of these two conditions shown in the Figure $8(\mathrm{~b})$ is far less than the typical knock condition. So the knock intensity of cylinder 3 and cylinder 1 is lower than the typical knock conditions show in the Figure 7. 


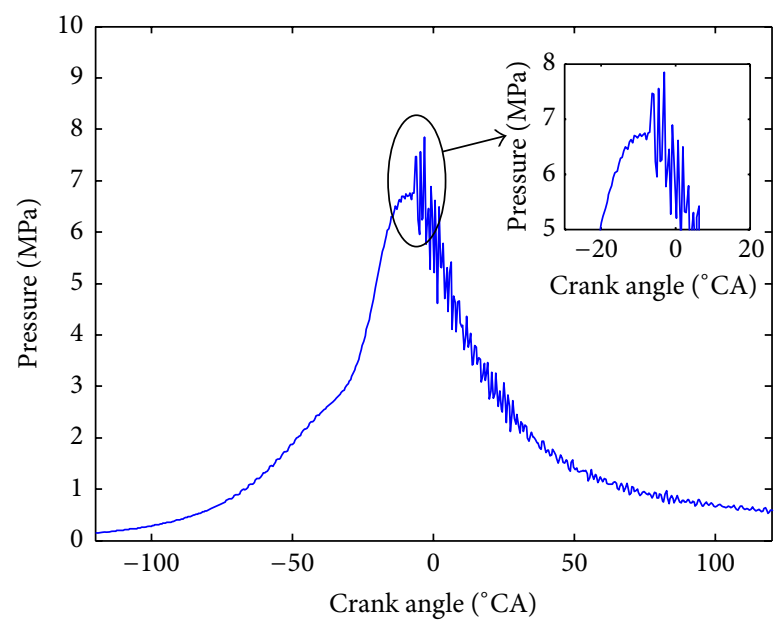

(a)

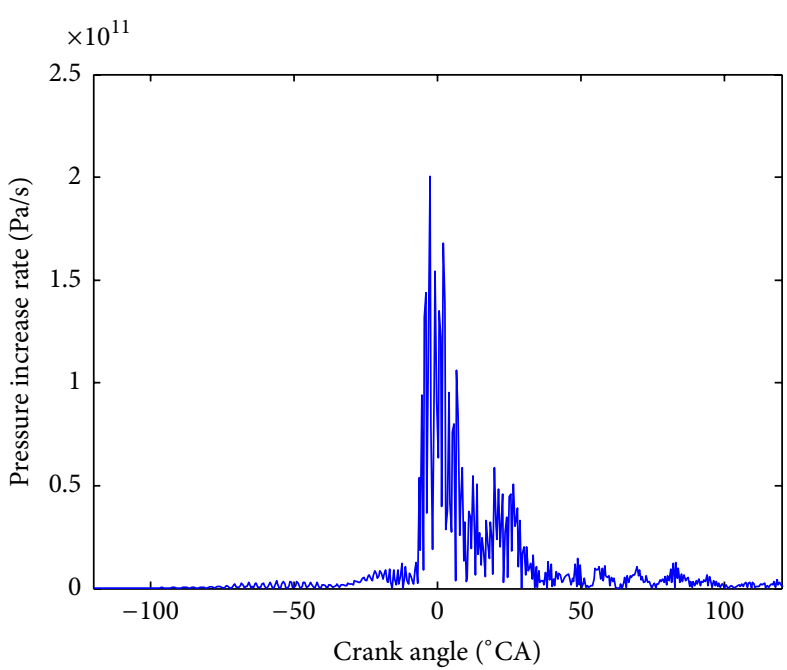

(b)

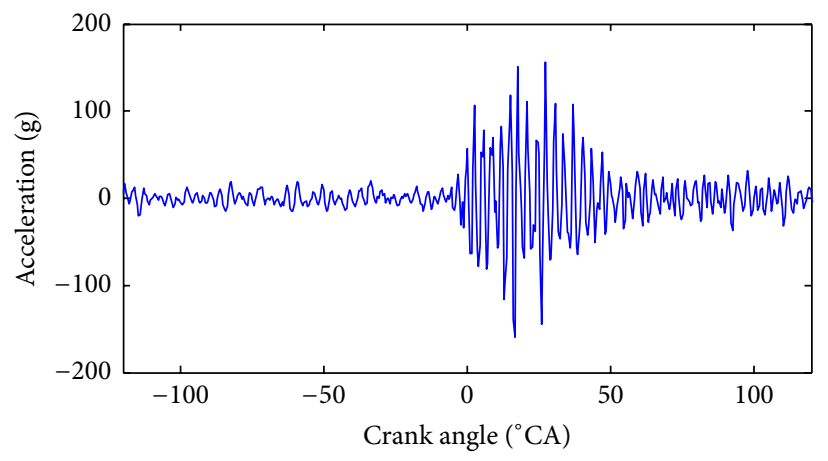

(c)

Figure 7: (a) Cylinder pressure signal of typical knock condition. (b) Cylinder pressure increased rate signal of typical knock condition. (c) Cylinder block vibration signal of typical knock condition.

Due to the fact that the knock intensity is lower, the vibration acceleration amplitude of cylinder 1 and cylinder 3 cycles is far less compared to the typical knock condition. And, based on the vibration signals in Figure 8(c), hardly any evidence indicates that knock combustion occurred in the cylinder 1 and cylinder 3 cycles can be found.

Because cylinder pressure oscillations in a SI engine can precisely characterize knock, the pressure signals of 4 cylinders shown in Figure 8(a) were first decomposed to many IMFs with a CEEMD transform for further comparison with the results obtained from the cylinder block vibration signals. The CEEMD results of 4 cylinders conditions are shown in Figures 9(a)-9(d).

From these pictures, it can be found that the high frequency signals obviously constituted in IMF1 IMF5 and IMF6 IMF10 were constituted by the middle or low frequency signals. In the Figure 9(a), there is an obvious impact (starting at approximately $0.028 \mathrm{~s}$ ) that can clearly be seen in the transform cylinder pressure signals from IMF1. And this moment the cylinder pressure of cylinder 1 reach the peak amplitude. As is shown in the Figure 9(c), it can be found that the impact in the IMF1, starting at approximately $0.006 \mathrm{~s}$, is also the moment of cylinder 3 pressure reach the peak amplitude. But, in Figures 9(b) and 9(d), there is no obvious impact that occurred in the IMF1; combined with the prior result shown in the Figures 8(a) and 8(b), it can be concluded that the CEEMD algorithm can extract the knock feature from cylinder pressure signals even the knock intensity is not heavy.

The result of CEEMD transformed from the cylinder block vibration signal is shown in Figure 10; from Figure 10, it is clear that a series of impacts (starting at approximately $0.006 \mathrm{~s}$ and $0.028 \mathrm{~s}$ ) can clearly be seen in the transform vibration signals from IMF1. Based on Figure 8(a), this moment is the same time of the cylinder 1 and cylinder 3 cycles reaching the peak pressure, and these two cycles are knock conditions. On the other hand, at the time of others two cycles reach the peak pressure (starting at approximately $0.013 \mathrm{~s}$ and $0.021 \mathrm{~s}$ ), the IMF1 result have no obvious impact.

Based on above investigations, it can be concluded that the CEEMD algorithm can extract the knock feature from both cylinder pressure signals and cylinder block vibration signals. Furthermore, the vibration signal is measured by a vibration acceleration sensor arranged in the cylinder 


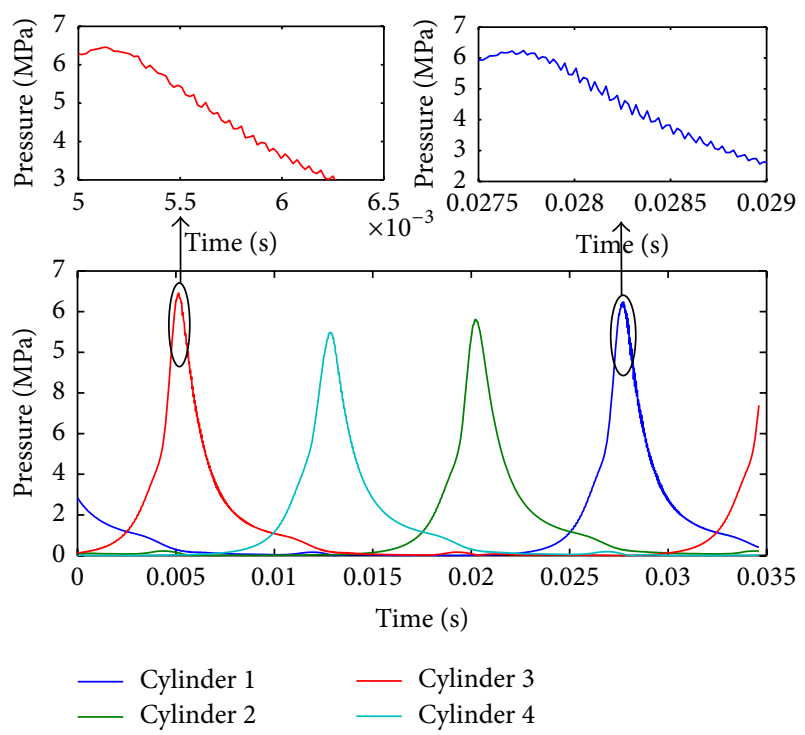

(a)

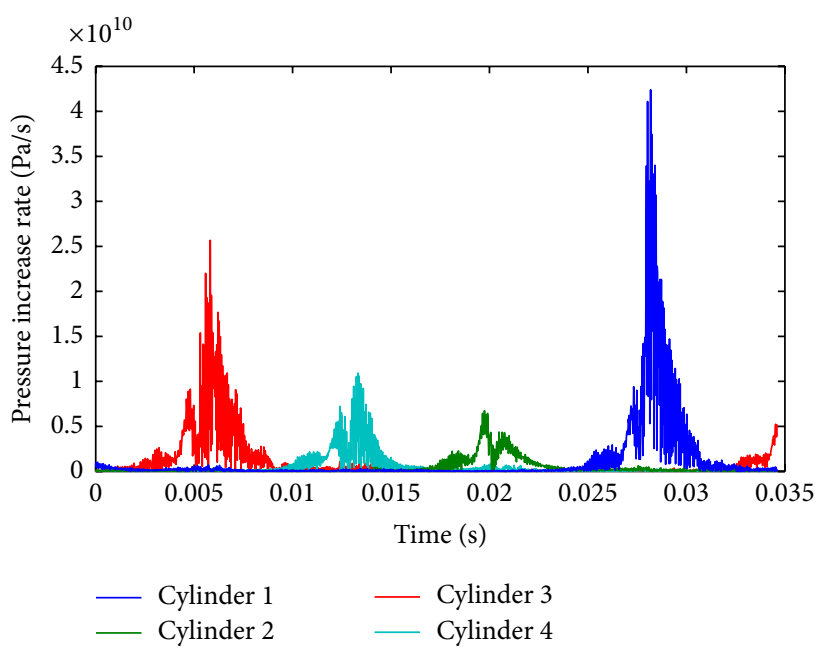

(b)

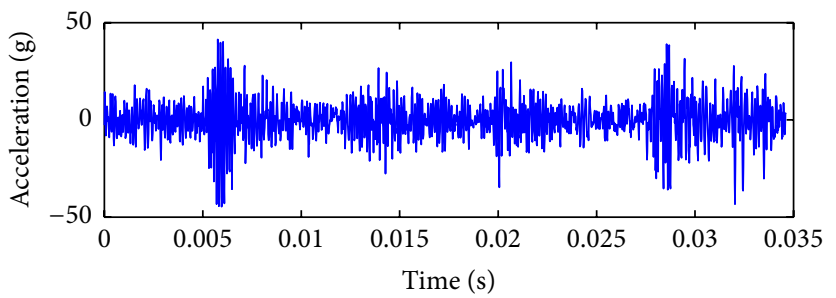

(c)

FIgURE 8: (a) Cylinder pressure signal. (b) Cylinder pressure increase rate. (c) Cylinder block vibration signal.

block of cylinder 2; after CEEMD decomposition, we can successfully detect the knock characteristics of cylinder 1 and cylinder 3. So we can use only one acceleration senor to detect knock characteristic of each cylinder in the multicylinder engine.

In order to further investigate the feasibility and effectiveness of CEEMD method in knock characteristic extraction, the vibration signals shown in Figure 8(c) were analyzed by band-pass filter and Discrete Wavelet Transform (DWT) for a comparison. Though the following Hilbert transform shows that in this engine, the instantaneous frequency of knock characteristics in vibration signal is concentrated in the $5000-10000 \mathrm{~Hz}$, the frequency pass band is $5000-$ $10000 \mathrm{~Hz}$. And, based on DWT, the measured signals shown in Figure 8(c) were decomposed to level 3 as well. In this work, the $\mathrm{db} 5$ wavelet has been used.

The filter result of vibration signals is illustrated in Figure 11(a), and the DWT result of the same condition is shown in the Figure 11(b). As a comparison, the IMF1 of CEEMD result is shown in Figure 11(c).

From Figure 11(a), two impacts following the peak pressure of cylinder 3 and cylinder 1 (starting at approximately $0.006 \mathrm{~s}$ and $0.028 \mathrm{~s}$ ) can be recognized in the filter result, which is similar to the CEEMD results displayed in Figure 11(c), but, at the moment of normal combustion conditions cylinder 2 and cylinder 4 reaching the peak pressure, the impacts is still exist. Although the amplitude of these two impacts is less than original vibration signal shown in Figure 8(c), the filter result is not as good as the CEEMD method.

And the DWT result of the same condition is shown in Figure 11(b); from this picture, it can be found that two impacts induced by knock combustion in cylinder 1 and cylinder 3 can be recognized in the subbands $d 1$ and $d 2$, but, compared to the Figure 11(c), it can be found that the knock impact in the DWT result is not as obvious as CEEMD result.

In order to better illustrate the advantages of CEEMD method, another condition running under $2800 \mathrm{rpm}$ is shown in Figure 12. Figures 12(a) and 12(b) are pressure and pressure increase rate curves of each cylinder, and Figure $12(\mathrm{c})$ is the second cylinder engine vibration curve at this moment. From left to right is 1-3-4-2 cylinder. From Figures 12(a) and 12(b) it can be found that cylinder 3 pressure fluctuates sharply, and the amplitude of cylinder 3 pressure increase rate is $1.2 \times 10^{11} \mathrm{~Pa} / \mathrm{s}$, larger than the knocking condition shown in Figure 8(b); in that condition, the max amplitude of cylinder pressure increase rate is $4.2 \times 10^{10} \mathrm{~Pa} / \mathrm{s}$. So it can be concluded that, in this condition, heavy knock occurred in cylinder 3 .

And, in addition to cylinder 3 , the cylinder pressure curve of cylinder 2 and cylinder 4 is relatively smooth, does not fluctuate, and illustrates these two cylinders did not have 

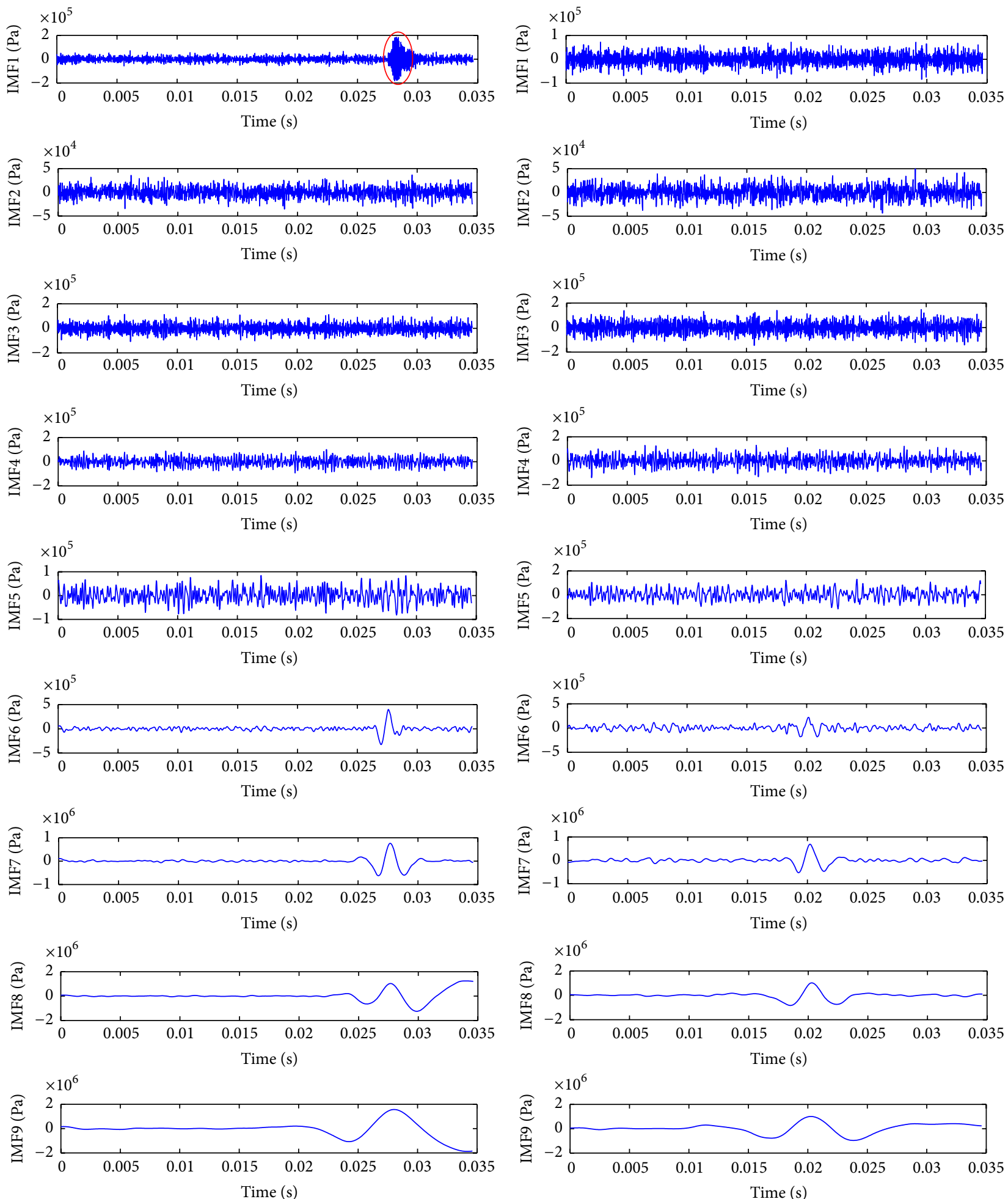

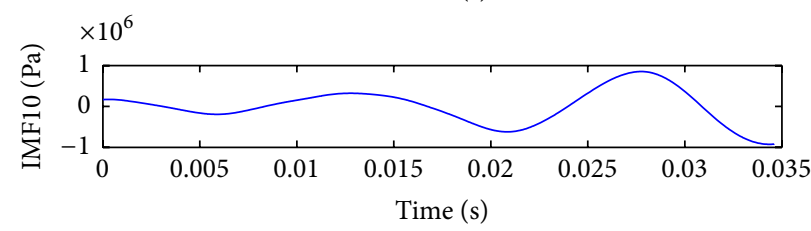

(a)

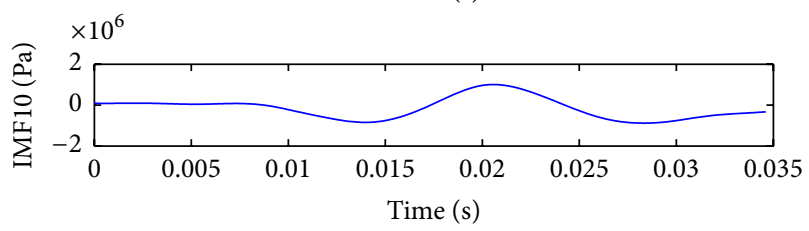

(b)

Figure 9: Continued. 

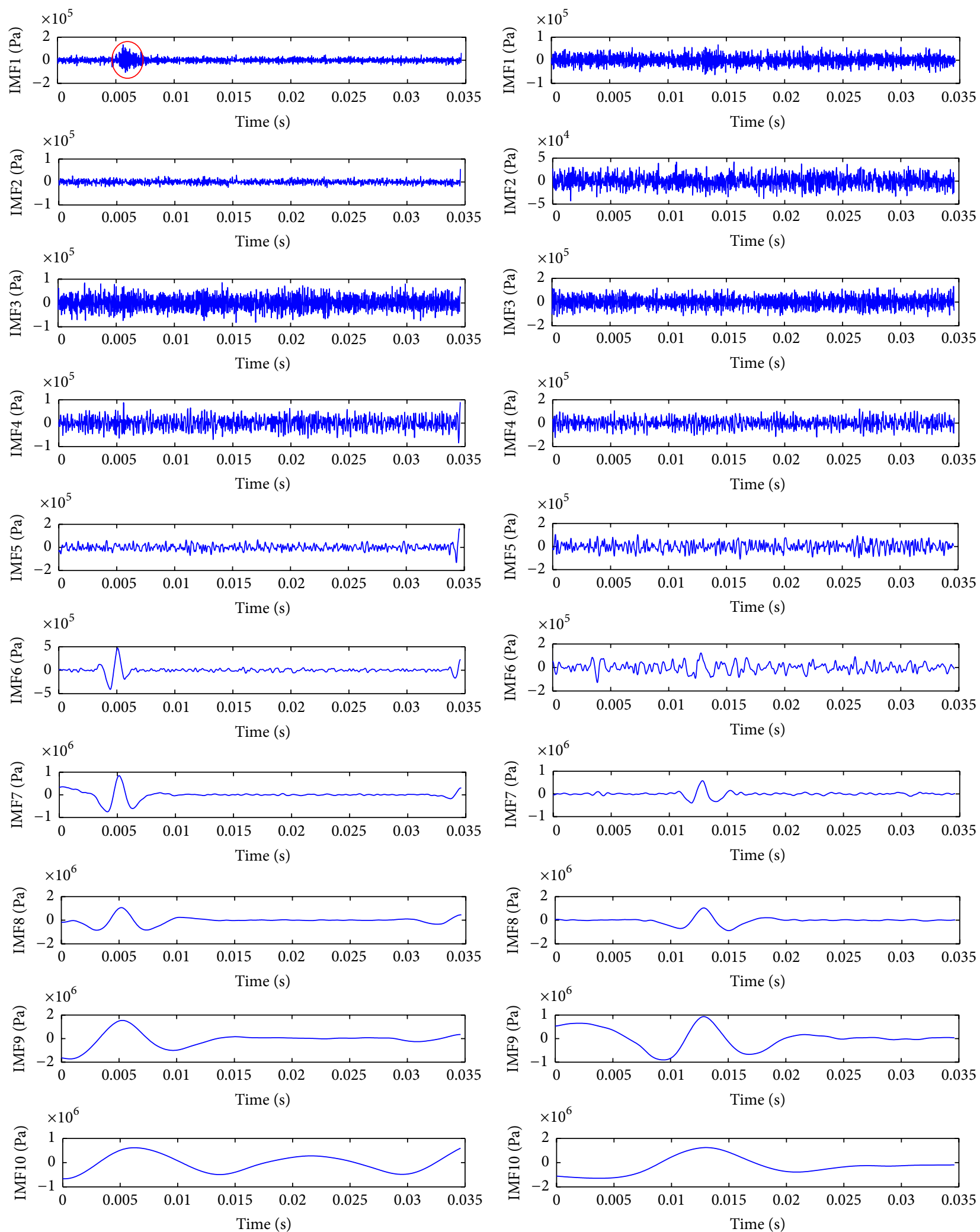

(c)

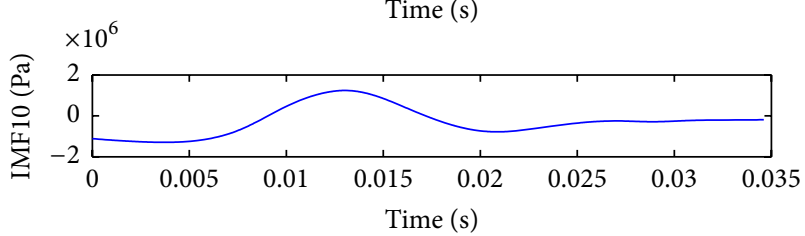

(d)

FIGURE 9: (a) Decomposition Results of CEEMD for cylinder pressure signal of cylinder 1. (b) Decomposition Results of CEEMD for cylinder pressure signal of cylinder 2. (c) Decomposition Results of CEEMD for cylinder pressure signal of cylinder 3. (d) Decomposition Results of CEEMD for cylinder pressure signal of cylinder 4 . 

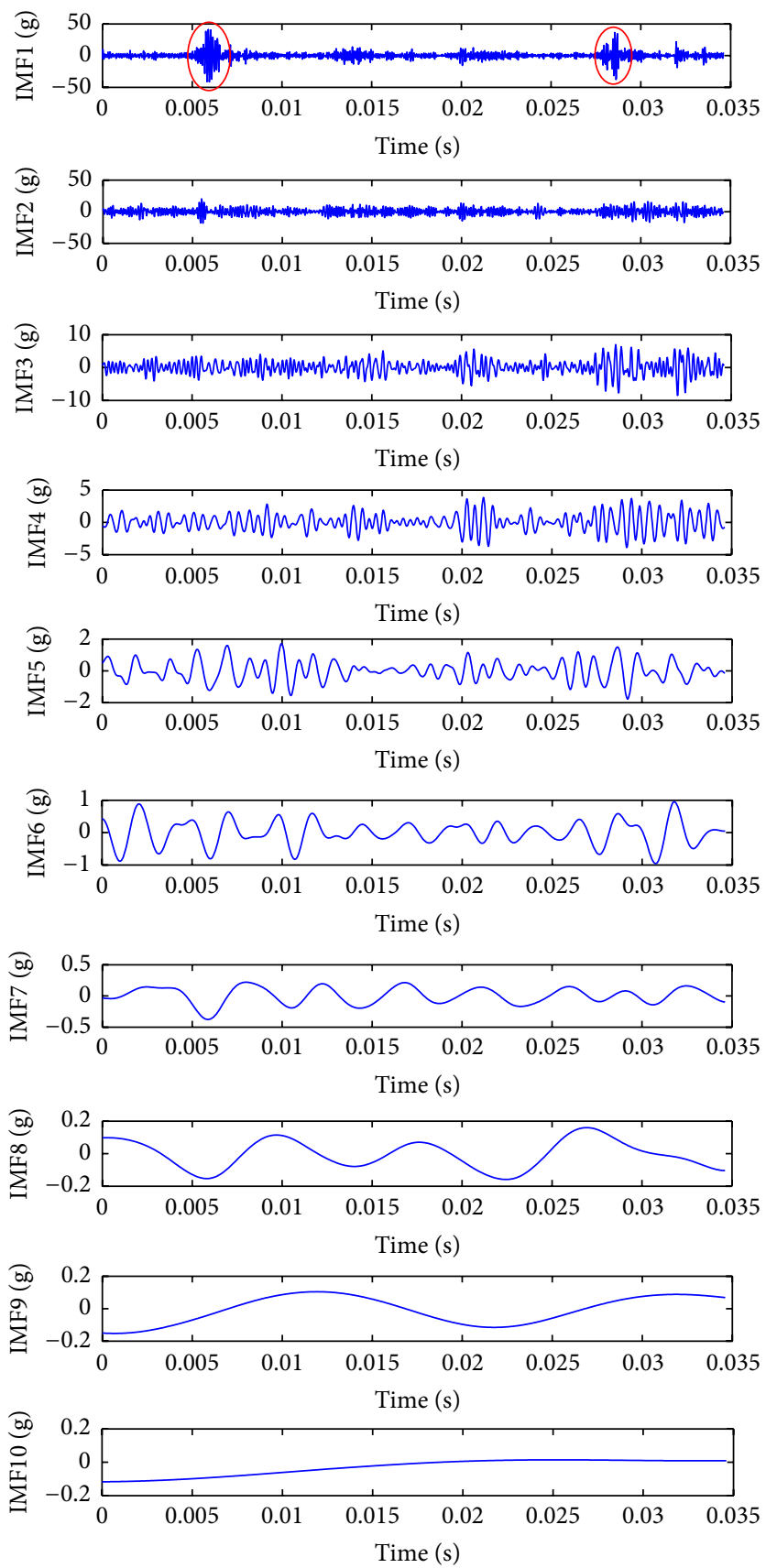

FIGURE 10: Decomposition results of CEEMD for cylinder block vibration signal.

knock. But from Figure 12(a) it can be also found that cylinder 1 pressure curve showed high frequency fluctuations, but the amplitude is smaller than other knock conditions, and the amplitude of cylinder pressure increase rate is $1.5 \times$ $10^{10} \mathrm{pa} / \mathrm{s}$, higher than normal combustion condition, so it can be concluded that cylinder 1 have light knock. But, as is shown of Figure 12(c), at the moment of cylinder 1 pressure fluctuate, we cannot find obviously knock characteristic in the original vibration signal.
The result of CEEMD transform is shown in Figure 13. Since the paper has proved that the knock characteristics mainly exist in the IMF1, in order to better compare with the filtering results, here only the IMF1 component results is listed. From Figure 13, it can be seen that the IMF1 component has a very obvious impact at $0.015 \mathrm{~s}$, and this impact is induced by heavy knock in cylinder 3 . In addition, the IMF1 component also has impact at $0.004 \mathrm{~s}$, and cylinder 1 pressure fluctuated at this moment; although the amplitude of this 


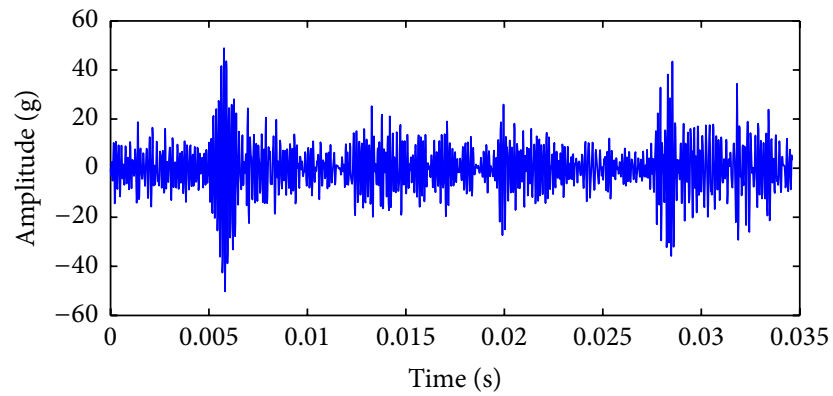

(a)
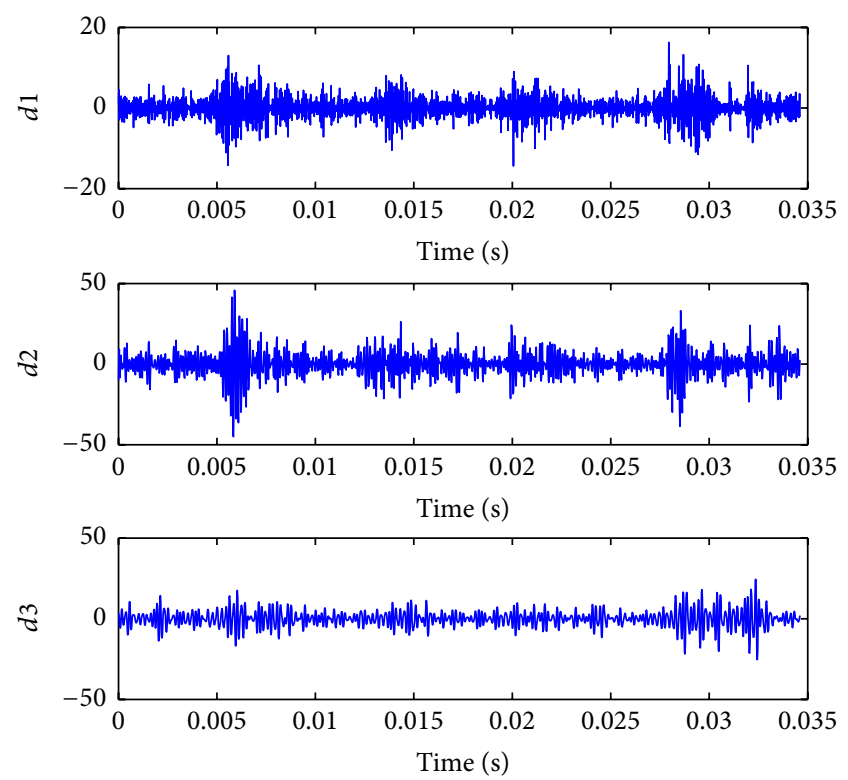

(b)

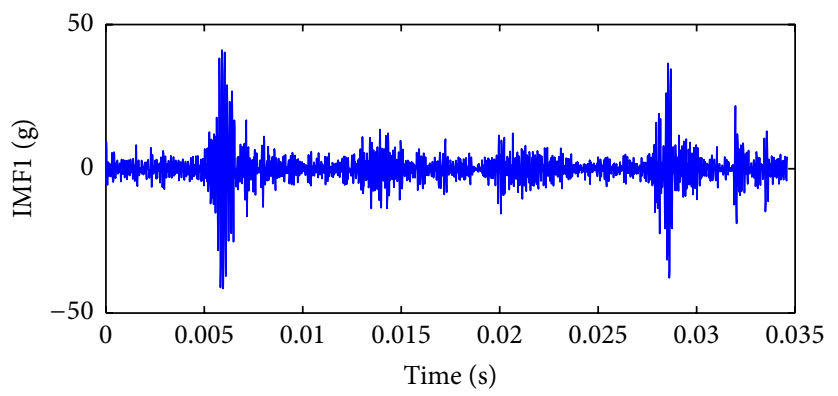

(c)

Figure 11: (a) The filter result of cylinder block vibration signal. (b) The DWT result of cylinder block vibration signal. (c) The IMF1 of CEEMD result of cylinder block vibration signal.

impact is less than the cylinder 3 condition, it is much greater than that of the normal combustion conditions (cylinder 2 and cylinder 4 ). This shows that the CEEMD method can identify light knock characteristic from vibration signal, and the knock characteristic is included in IMF1.

The result of band pass filter is shown in Figure 14. From this picture, it can be found that an impact following the peak pressure of cylinder 3 occurred in $0.015 \mathrm{~s}$; this impact is the characteristic of heavy knock in cylinder 3. But, at the moment of cylinder 1 knocking, the amplitude of the band pass filter results is not significantly greater compared to the moment of cylinder 2 and cylinder 4 reaching the peak pressure $(0.025 \mathrm{~s}$ and $0.036 \mathrm{~s})$. So, the band pass filter cannot find the light knock characteristic occurred in cylinder 1.

The DWT result of this condition is shown in Figure 15. From Figure 15, an impact following the peak pressure of cylinder 3 can be recognized in $d 1-d 3$, which is similar to the CEEMD results displayed in Figure 13, but, at the moment knock occurred in cylinder $1(0.004 \mathrm{~s})$, there was no obvious impact. So, comparing Figure 15 with Figure 13, the characteristic induced by knock in cylinder 1 is absent in the analytical result of DWT.
From these result, it can be concluded that, for extracting the light knock characteristics, CEEMD method is better than band pass filter and Discrete Wavelet Transform (DWT) method.

In order to further analysis that frequency characteristics of engine knock, the IMF1s obtained from conditions shown in Figure 8 are taking Hilbert transform. The Hilbert results are shown in Figures 16(a)-16(d) and 17. Figures 16(a)-16(d) show the Hilbert result of IMF1 decomposition from cylinder pressure signals and Figure 17 shows the Hilbert result of IMF1 decomposition from cylinder block vibration signals. From Figures 16(a) and 16(c), we can clearly see that at the moment of impact occurred of IMF1, and the instantaneous frequency of IMF1 concentrated in 15000-20000 Hz. But, in Figures 16(b) and 16(d), hardly any instantaneous frequency concentration in the IMF1 of cylinder 2 and cylinder 4 cycles can be found.

Similar, from Figure 17, it can be seen that, in the area of large instantaneous amplitude (knock area) of IMF1, the instantaneous frequency of IMF1 concentrated in the 5000$10000 \mathrm{~Hz}$. And at the moment of cylinder 2 and cylinder 4 cycles (normal conditions) reaching the peak pressure, 


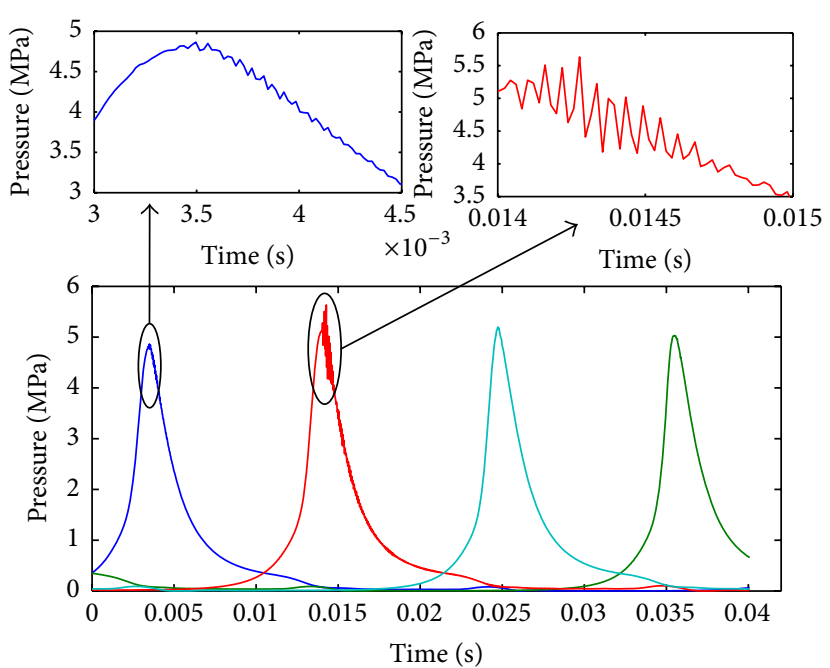

$\begin{array}{ll}\text { Cylinder } 1 & \text { Cylinder } 3 \\ \text { Cylinder } 2 & \text { Cylinder } 4\end{array}$

(a)

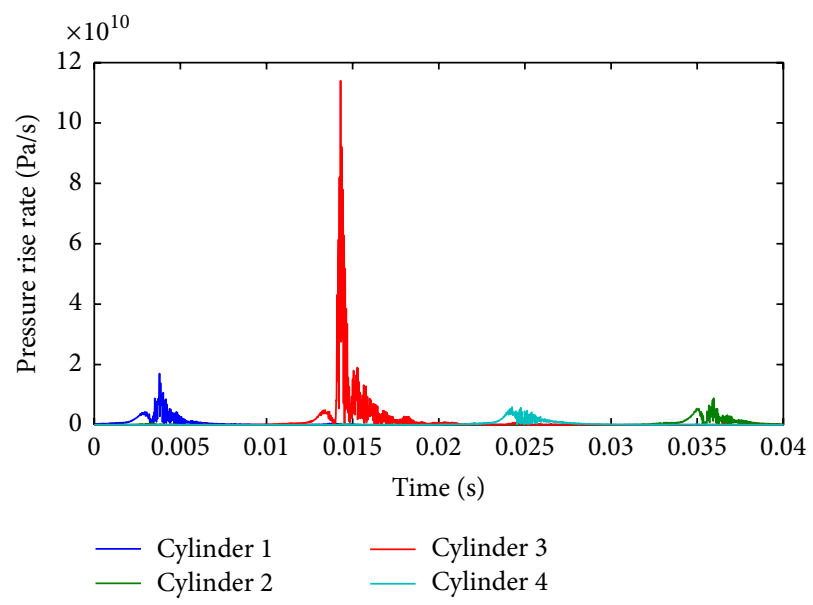

(b)

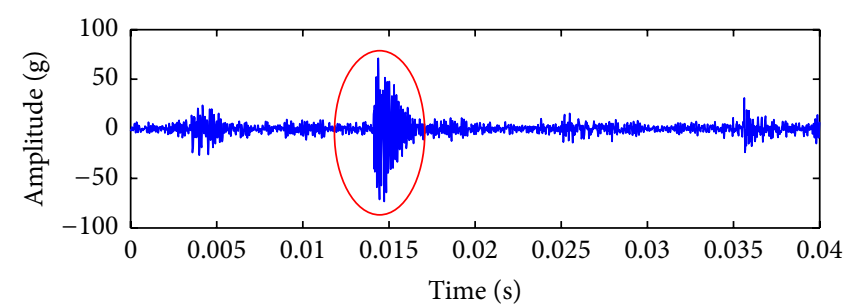

(c)

Figure 12: (a) Cylinder pressure signal under 2800 rpm. (b) Cylinder pressure increase rate under $2800 \mathrm{rpm}$. (c) Cylinder block vibration signal under $2800 \mathrm{rpm}$.

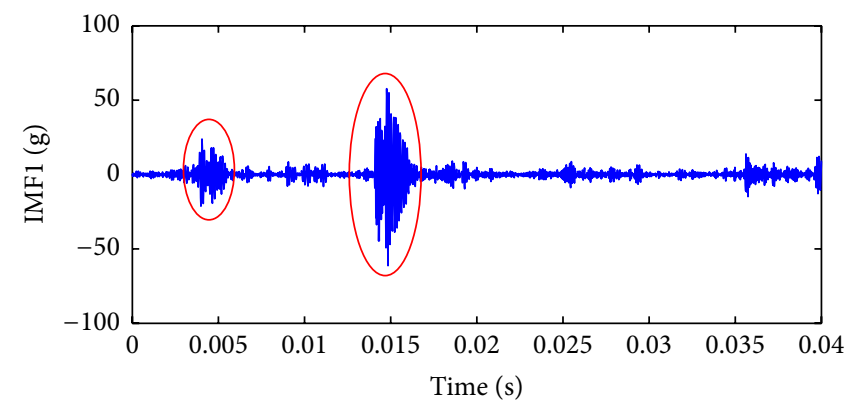

FIGURE 13: The IMF1 of CEEMD result of cylinder block vibration signal measured at $2800 \mathrm{rpm}$ condition.

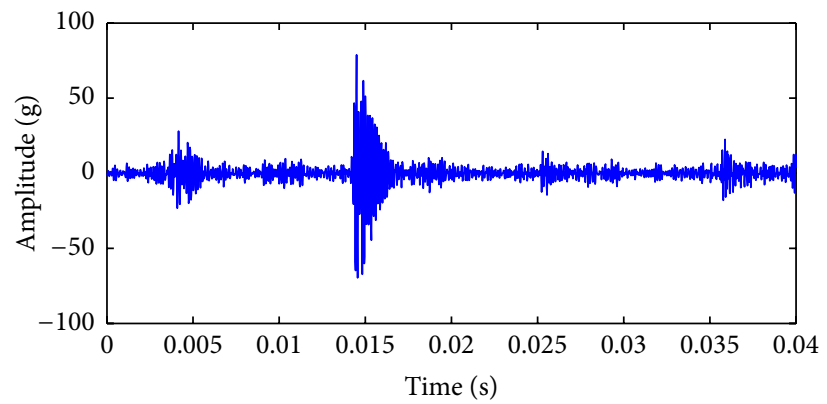

FIGURE 14: The band pass filter result of cylinder block vibration signal measured at $2800 \mathrm{rpm}$ condition. 

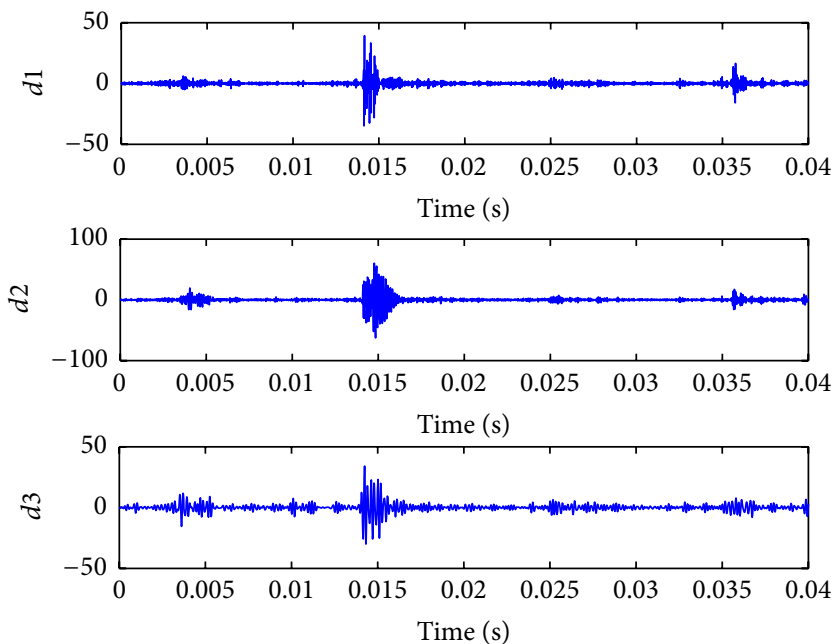

FIGURE 15: The DWT result of cylinder block vibration signal measured at $2800 \mathrm{rpm}$ condition.

there is no frequency concentration that occurred. So it can be concluded that the instantaneous frequency of knock characteristics mainly concentrates in a particular frequency range.

4.2. Definition of Knock Intensity. In order to evaluate the engine knock more intuitively, a knock intensity factor $(K)$ is needed to describe the intensity of knock. Since the most widely used method of measuring knock is using vibration signals, we use the IMF1 obtained from cylinder block vibration signal to calculate the knock evaluation parameters.

It is popular to use signal energy to calculate the knock intensity in previous studies. The energy based method is equivalent in both the frequency and time domains. In this paper, $K$ is defined from the ratio of average-energy of CEEMD transform result as the following expression:

$$
K=\frac{\sum_{i=1}^{N} x(i)^{2}}{\sum_{i=1}^{N} y(i)^{2}} .
$$

In the above equation, $N$ is the data number in the knock window of IMF1. $x(i)$ is the $i$ th data point of IMF1s in the knock window and $y(i)$ is the $i$ th data point of IMF1s in the reference window. To use this equation, the knock window and reference window need to be established. According to the different condition, different intensity of knock conditions was observed; in this engine, the impact of IMF1 of cylinder block vibration signal during knock combustion cycle, generally, lasts about $60^{\circ} \mathrm{CA}$ and the start point is approximately at $15^{\circ} \mathrm{CA}$ after ignition. Figure 18 is the cylinder pressure curve, cylinder block vibration curve, and vibration's IMF1 curve of the typically knock condition shown in Figure 7. From Figure 18, it can be found that the impact of IMF1 of cylinder pressure signal lasts from $0^{\circ} \mathrm{CA}$ to $60^{\circ} \mathrm{CA}$, and the ignition advance angle of this condition is $15^{\circ} \mathrm{CA}$. So, choose 60 degrees as knock window and reference window width. And choose 15 degrees after ignition as the start point of the knock window and the end point of reference window.

In this paper, 10 normal combustion conditions, 10 light knock conditions, and 10 heavy knock conditions were selected to calculate $K$ value of the knock evaluation parameters. The result is shown in Figure 19.

As is shown in Figure 19, it is clear that, in the normal combustion conditions, knock intensity factor $K$ values are all below 5, the maximum value is 2.3 , and $K$ values of light knock conditions are within the range of 15 to 25 , and $K$ value of heavy knock conditions are from 40 to 110 , and the gap between three kinds of working conditions is very obvious. So it can be concluded that using the knock intensity evaluation parameter $K$ to evaluate knock intensity can accurately distinguish between heavy knock, light knock, and normal combustion three states.

4.3. The Implementation of CEEMD Method. At present, the main engine of the gasoline engine is controlled by the knock control module, which mainly includes data acquisition unit and knock arithmetic unit. During the operation of the gasoline engine, the data acquisition unit collects the vibration signal through the vibration sensor arranged in the cylinder block and then converted signal into a digital signal through the AD conversion. Then the knock arithmetic unit is used to process the collected signal according to a narrow-band filter, to determine whether or not the knock is occurring in this working condition. Finally, according to the calculation results, the ignition advance angle is adjusted by Electronic Control Unit (ECU), which can realize the closedloop control of knock.

In order to apply this method to the vehicle, an appropriate single chip microcomputer (SCM) needs to be used as the knock arithmetic unit, and CEEMD algorithms will be written into the SCM. When the engines work, the SCM according to CEEMD program calculate the vibration signal 


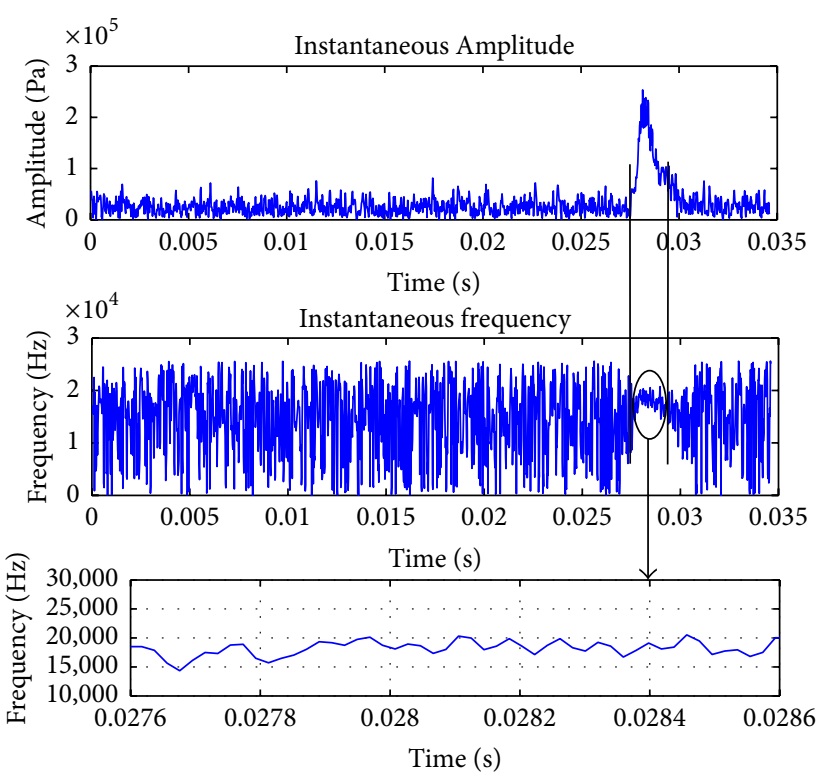

(a)

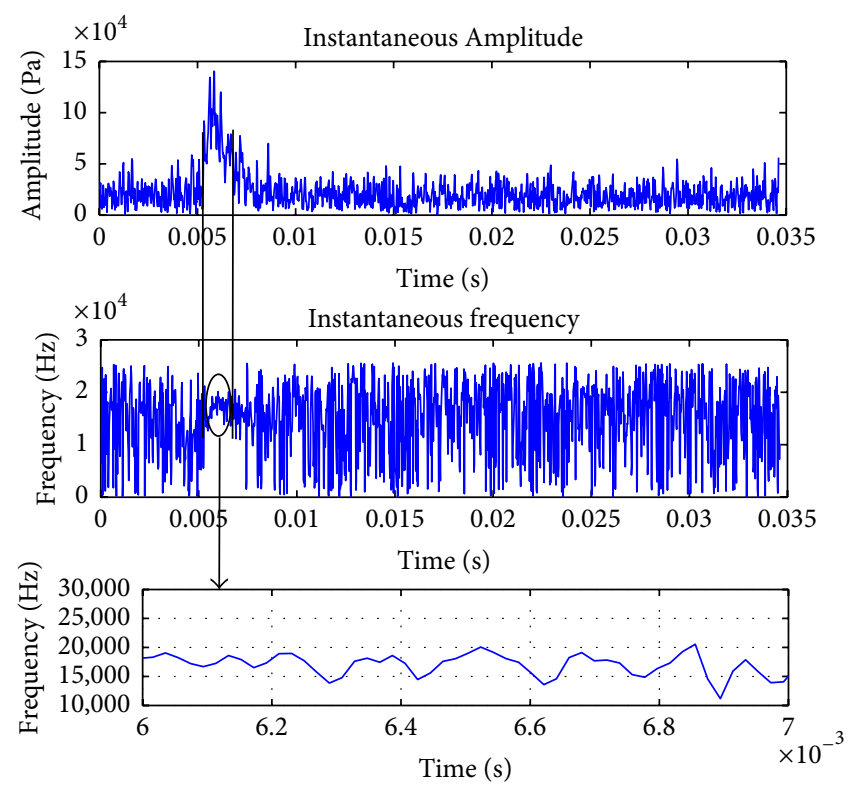

(c)
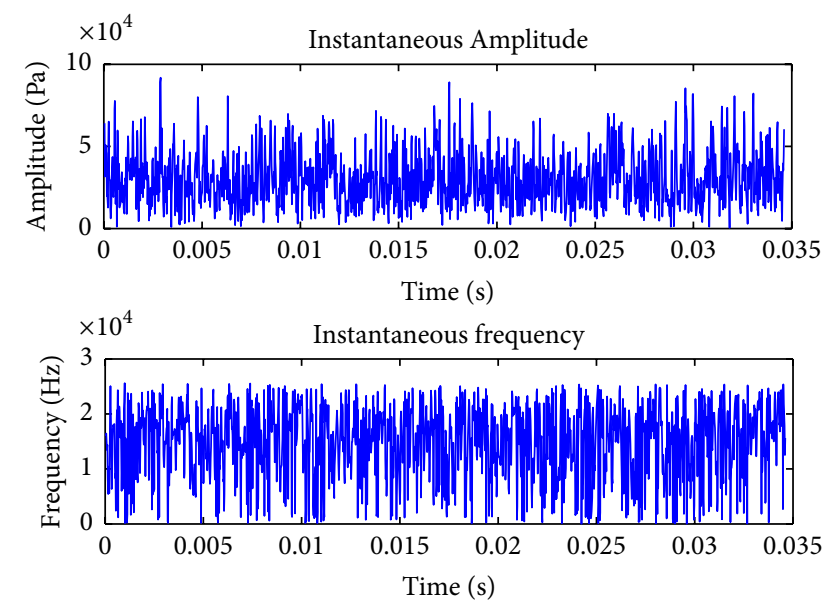

(b)
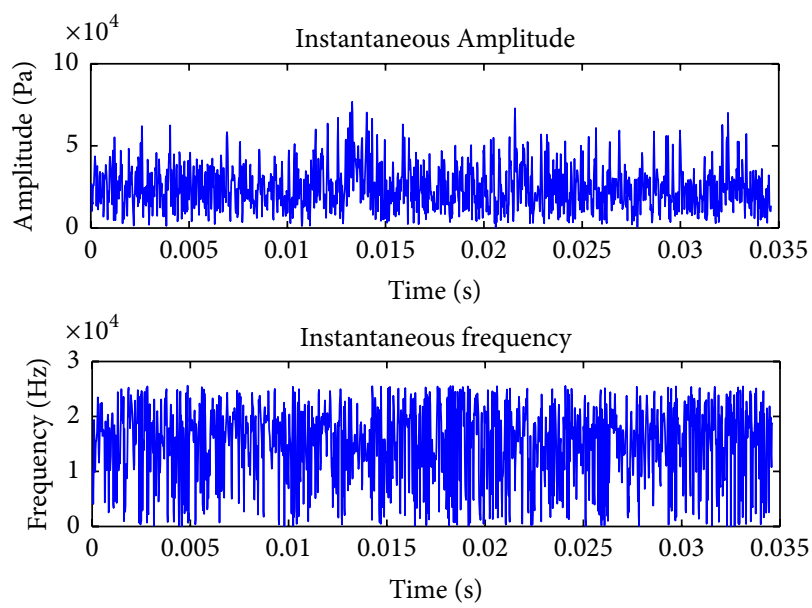

(d)

FIGURE 16: (a) Hilbert transform results of IMF1 for cylinder pressure signal of cylinder 1. (b) Hilbert transform results of IMF1 for cylinder pressure signal of cylinder 2. (c) Hilbert transform results of IMF1 for cylinder pressure signal of cylinder 3. (d) Hilbert transform results of IMF1 for cylinder pressure signal of cylinder 4.

input from the data acquisition unit and then output the calculation result to ECU, and ultimately the ECU adjust ignition advance angle to realize the knock closed-loop control.

Compared with traditional knock control method, using CEEMD method to detect knocking one only needs to use an appropriate single chip microcomputer (SCM) as knock arithmetic unit and write the corresponding program, without making changes to other parts of engine control system, and the cost of SCM is very low; therefore the implementation of CEEMD method does not significantly increase costs.

\section{Conclusions}

In this paper, a new knock detection method based on the CEEMD-Hilbert transform has been presented. 


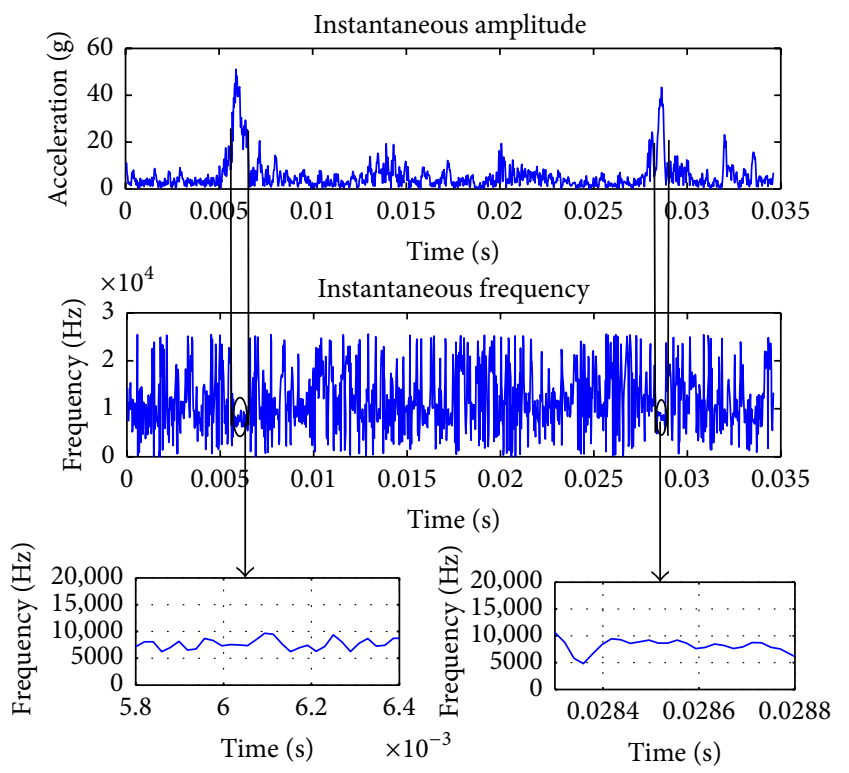

FIGURE 17: Hilbert transform results of IMF1 for cylinder block vibration signal.
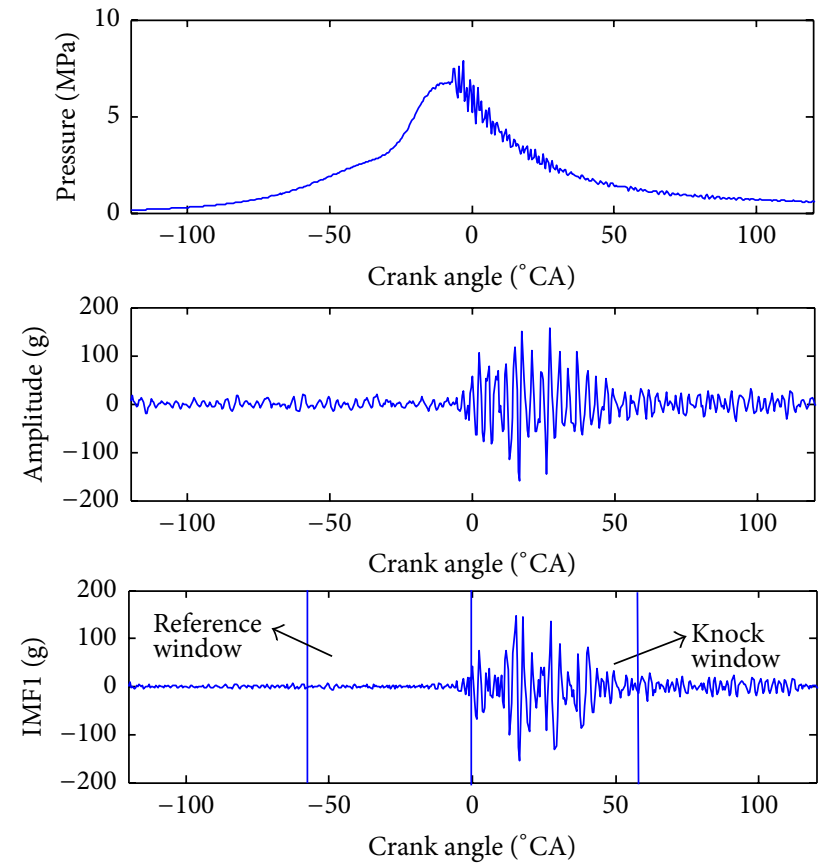

FIgURE 18: The cylinder pressure signal and the IMF1 of cylinder block vibration signal.

The observations and conclusions of the study are summarized as follows:

(1) The CEEMD algorithm can effectively extract the knock shock characteristics (include light knock) from both cylinder pressure signal and cylinder block vibration signal. Furthermore, to the multicylinder engines, the CEEMD algorithm can detect knock

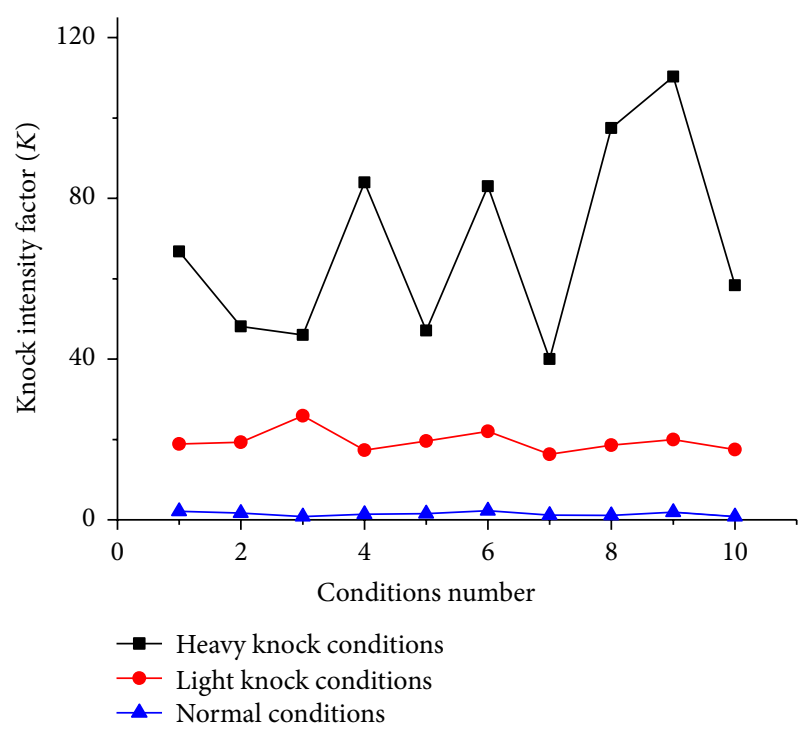

FIGURE 19: The knock evaluation parameter $K$ calculation results of vibration signal.

characteristics of each cylinder from vibration signals by using only one acceleration senor.

(2) Hilbert transform can analyze the changes of instantaneous amplitude and instantaneous frequency in the knock combustion process. The Hilbert transform result shows that the energy of knock shock areas has the phenomenon of frequency concentration in both cylinder pressure signal and cylinder block vibration signal.

(3) Components containing the knock characteristics of CEEMD decomposition results were analyzed, and the knock intensity evaluation parameter $K$ was calculated. The results show that the knock intensity evaluation parameter $K$ can accurately distinguish between heavy knock, light knock, and normal combustion three states.

\section{Conflict of Interests}

The authors declared that they have no conflict of interests regarding the publication of this paper.

\section{Acknowledgment}

This research is supported by National Science and Technology Support Program of China: Vibration and Noise Reduction Technology Research and Application of Bulldozers and Other Earth Moving Machinery (Grant no. 2015BAF07B04).

\section{References}

[1] E. Galloni, "Dynamic knock detection and quantification in a spark ignition engine by means of a pressure based method," Energy Conversion and Management, vol. 64, pp. 256-262, 2012. 
[2] W. Li, Y. Wang, L. Zhou, and L. Su, "Study on improvement of fuel economy and reduction in emissions for stoichiometric gasoline engines," Applied Thermal Engineering, vol. 27, no. 1718, pp. e2919-e2923, 2007.

[3] X. Zhen, Y. Wang, S. Xu et al., "The engine knock analysis-an overview," Applied Energy, vol. 92, pp. 628-636, 2012.

[4] L. Ni, Y. Jian-guo, and Z. Rui, "Gasoline engine knock feature extraction based on ensemble empirical mode decomposition," Journal of Mechanical Engineering, vol. 51, no. 2, pp. 148-154, 2015 (Chinese).

[5] J. Kearney M, "Knock signal conditioning using the discrete Fourier transform and variable detection window length," SAE Technical Paper 2007-01-1509, 2007.

[6] S. Vulli, J. F. Dunne, R. Potenza, D. Richardson, and P. King, "Time-frequency analysis of single-point engine-block vibration measurements for multiple excitation-event identification," Journal of Sound and Vibration, vol. 321, no. 3-5, pp. 1129-1143, 2009.

[7] B. Samimy and G. Rizzoni, "Mechanical signature analysis using time-frequency signal processing: application to internal combustion engine knock detection," Proceedings of the IEEE, vol. 84, no. 9, pp. 1330-1343, 1996.

[8] J. Antoni, J. Daniere, and F. Guillet, "Effective vibration analysis of IC engines using cyclostationarity. Part I-a methodology for condition monitoring," Journal of Sound and Vibration, vol. 257, no. 5, pp. 815-837, 2002.

[9] J. Chang, M. Kim, and K. Min, "Detection of misfire and knock in spark ignition engines by wavelet transform of engine block vibration signals," Measurement Science and Technology, vol. 13, no. 7, pp. 1108-1114, 2002.

[10] Z. Zhang and E. Tomita, "Knocking detection using wavelet instantaneous correlation method," JSAE Review, vol. 23, no. 4, pp. 443-449, 2002.

[11] J. Borg, G. Saikalis, S. Oho, and K. Cheok, "Knock signal analysis using the discrete wavelet transform," SAE Technical Paper 2006-01-0226, 2006.

[12] J. G. Yang, X. F. Liu, and B. Lin, "DWT based knock detection and knock intensity judgment for a gasoline engine," Transactions of CSICE, vol. 21, pp. 233-238, 2003 (Chinese).

[13] N. Li, J. Yang, R. Zhou, and Q. Wang, "Knock detection in spark ignition engines using a nonlinear wavelet transform of the engine cylinder head vibration signal," Measurement Science and Technology, vol. 25, no. 11, Article ID 115002, 2014.

[14] N. E. Huang, Z. Shen, S. R. Long et al., "The empirical mode decomposition and the Hilbert spectrum for nonlinear and non-stationary time series analysis," Proceedings of the Royal Society, vol. 44, pp. 903-995, 1998.

[15] X. Zheng and Z. Hao, "Diagnosis of valve-slap of diesel engine with EEMD-EMD-AGST approach," Transactions of Tianjin University, vol. 18, no. 1, pp. 26-32, 2012.

[16] Z. H. Wu and N. E. Huang, "Ensemble empirical mode decomposition: a noise-assisted data analysis method," Advances in Adaptive Data Analysis, vol. 1, no. 1, pp. 1-41, 2009.

[17] J.-R. Yeh, J.-S. Shieh, and N. E. Huang, "Complementary ensemble empirical mode decomposition: a novel noise enhanced data analysis method," Advances in Adaptive Data Analysis, vol. 2, no. 2, article 135, 2010. 


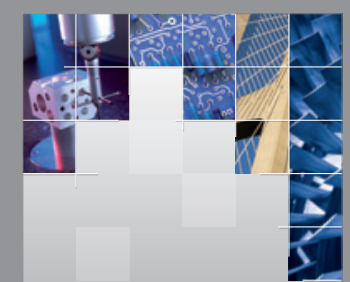

\section{Enfincering}
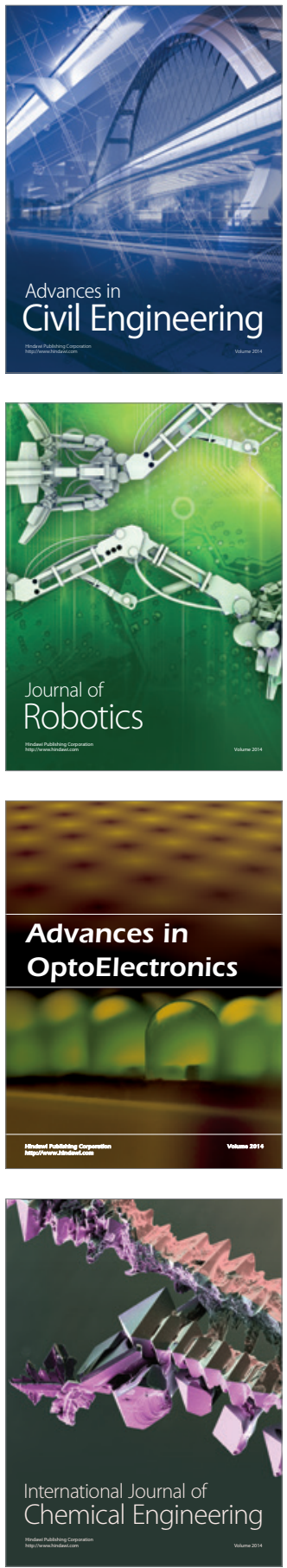

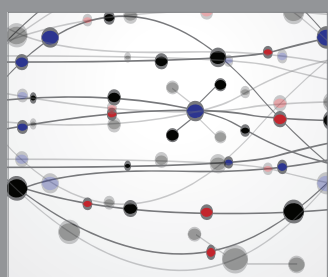

The Scientific World Journal

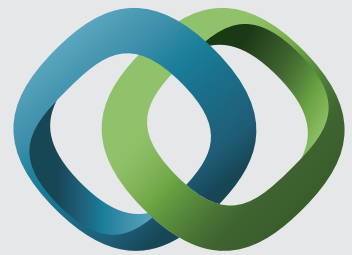

\section{Hindawi}

Submit your manuscripts at

http://www.hindawi.com
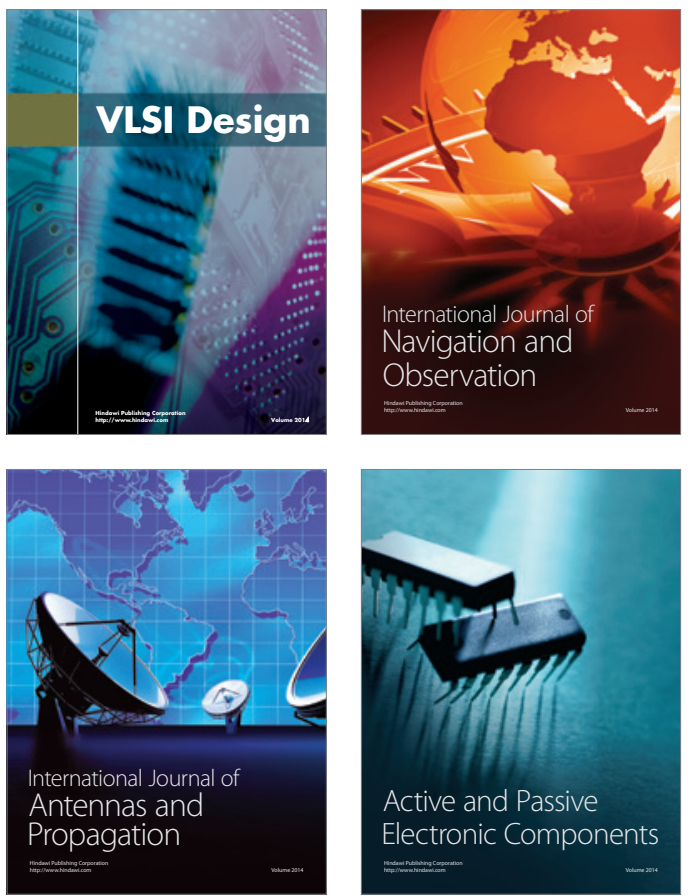
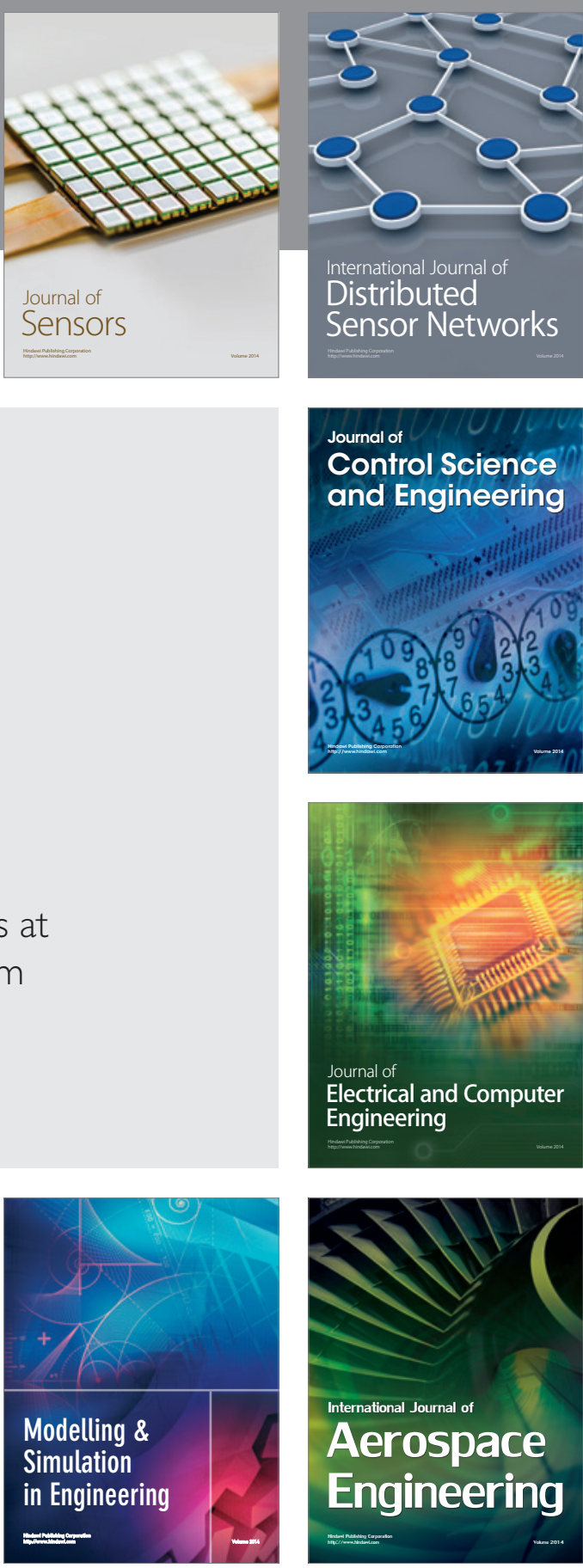

International Journal of

Distributed

Sensor Networks

Journal of

Control Science

and Engineering
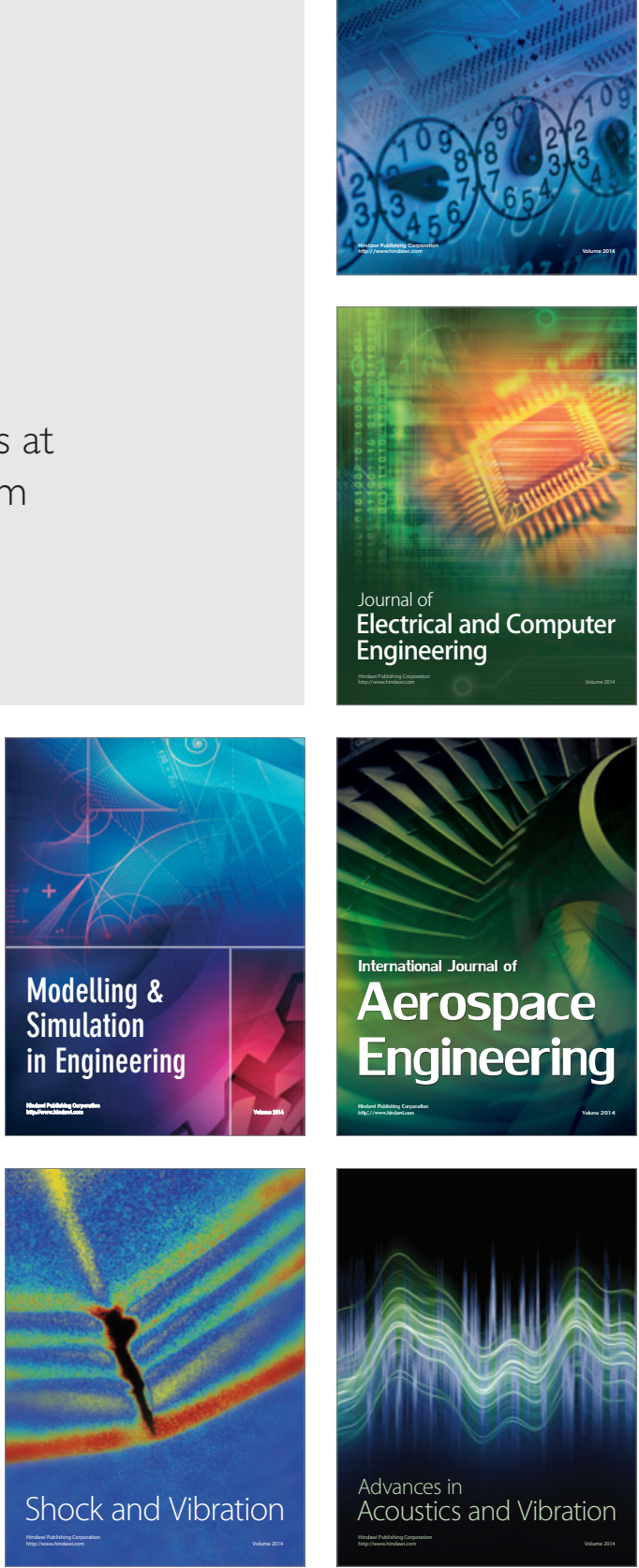